\title{
Influence of Coulombic Repulsion on the Dissociation Pathways and Energetics of Multiprotein Complexes in the Gas Phase
}

\author{
Igor Sinelnikov, Elena N. Kitova, and John S. Klassen \\ Department of Chemistry, University of Alberta, Edmonton, Alberta, Canada
}

\begin{abstract}
Thermal dissociation experiments, implemented with blackbody infrared radiative dissociation and Fourier-transform ion cyclotron resonance mass spectrometry, are performed on gaseous protonated and deprotonated ions of the homopentameric B subunits of Shiga toxin $1\left(\mathrm{Stx} 1 \mathrm{~B}_{5}\right)$ and Shiga toxin $2\left(\mathrm{Stx} 2 \mathrm{~B}_{5}\right)$ and the homotetramer streptavidin $\left(\mathrm{S}_{4}\right)$. Dissociation of the gaseous, multisubunit complexes proceeds predominantly by the loss of a single subunit. Notably, the fractional partitioning of charge between the product ions, i.e., the leaving subunit and the resulting multimer, for a given complex is, within error, constant over the range of charge states investigated. The Arrhenius activation parameters $\left(E_{a}, A\right)$ measured for the loss of subunit decrease with increasing charge state of the complex. However, the parameters for the protonated and deprotonated ions, with the same number of charges, are indistinguishable. The influence of the complex charge state on the dissociation pathways and the magnitude of the dissociation $\mathrm{E}_{\mathrm{a}}$ are modeled theoretically with the discrete charge droplet model (DCDM) and the protein structure model (PSM), wherein the structure of the subunits is considered. Importantly, the major subunit charge states observed experimentally for the Stx $1 \mathrm{~B}_{5}^{n \pm}$ ions correspond to the minimum energy charge distribution predicted by DCDM and PSM assuming a late dissociative transition-state (TS); while for structurally-related Stx2 $\mathrm{B}_{5}^{n+}$ ions, the experimental charge distribution corresponds to an early TS. It is proposed that the lateness of the TS is related, in part, to the degree of unfolding of the leaving subunit, with Stx1 B being more unfolded than Stx2 B. PSM, incorporating significant subunit unfolding is necessary to account for the product ions observed for the $S_{4}^{n+}$ ions. The contribution of Coulombic repulsion to the dissociation $\mathrm{E}_{\mathrm{a}}$ is quantified and the intrinsic activation energy is estimated for the first time. (J Am Soc Mass Spectrom 2007, 18, 617-631) (c) 2007 American Society for Mass Spectrometry
\end{abstract}

$\mathrm{T}$ The majority of cellular proteins exist and function as multimeric complexes. Consequently, the characterization of protein assemblies, their structure, stability, and biological function represent important analytical objectives. Mass spectrometry (MS), with its speed, sensitivity, and specificity, combined with electrospray ionization (ES), is an established tool for detecting specific multiprotein complexes in solution [1], the real time monitoring their assembly/disassembly [2] and subunit exchange reactions [3, 4], and identifying and quantifying their interactions with other biopolymers, as well as other ligands and cofactors [5]. Several comprehensive reviews of the applications of ES/MS to protein complexes have appeared, [1, 5-9], including a recent review by Robinson and coworkers [8].

Combined with gas-phase ion activation techniques, which can be used to break the noncovalent interactions and, thereby, release individual subunits from the mul-

Published online January 3, 2007

Address reprint requests to Dr. J. S. Klassen, Department of Chemistry, University of Alberta, Edmonton, Alberta T6G 2G2, Canada. E-mail: john.klassen@ualberta.ca tiprotein complexes, ES/MS also holds promise as a tool for determining the subunit composition and, perhaps, the binding topology of heterocomplexes, as well as assessing the relative stability of structurally-related protein complexes in solution $[8,9]$. Now, however, the full potential of ES and tandem MS (i.e., ES/MS ${ }^{n}$ ) has not been fully realized. This is due in part to the resistance of multiprotein complexes to undergo extensive disassembly in the gas phase. Additionally, the relationship between the structure and stability of protein assemblies in solution and their dissociation pathways and stability in the gas phase is unclear and requires further elucidation.

ES/MS ${ }^{n}$ studies performed on a number specific homo- and heteroprotein complexes in the gas phase, including dimers [10-14], tetramers [15-17], pentamers [18], as well as large, multisubunit complexes [19-23], have revealed two general features related to the dissociation of multiprotein complexes in the gas phase. First, dissociation of gaseous multiprotein complexes normally occurs by the loss of a single subunit, independent of the number of protein subunits contained within the complex and the mechanism of assembly/ 
disassembly in solution. However, the loss of small multimers (e.g., dimers, trimers, etc.) as a minor dissociation channel, in addition to the loss of a single subunit, has been reported [18]. A second general characteristic of the dissociation of gaseous multiprotein complexes is the ejection of the subunit with a disproportionately large fraction (in terms of its mass) of the total charge of the complex.

The enrichment of charge on the leaving subunit during the dissociation of multiprotein complexes may arise in a number of ways. Charge asymmetry may result from the differential charging of the protein subunits during the ES/desolvation process, if it leads to non-interconverting charge isomers [11]. The presence of charge isomers can be revealed from changes in the relative abundance of product ions detected in time-resolved dissociation experiments. To date, evidence of charge isomers has only been demonstrated for a single complex, the homodimer ecotin [11]. However, given the limited number of time-resolved dissociation studies reported [11, 18], it is unclear how widespread this phenomenon is. The charge distribution initially imparted by the ionization process may be altered by additional processes. For example, evidence of electrontransfer has been reported for complexes containing metalloproteins [24]. Charge separation involving the detachment of anions, perhaps buffer anions, from positively charged complexes during dissociation has also been suggested [25]. The product ion charge distribution may also be influenced by proton transfer between protein subunits upon activation [12, 18]. Direct evidence of rapid proton migration between subunits was first obtained from time-resolved thermal dissociation experiments performed on the protonated ions of the $B_{5}$ homopentamer of Shiga toxin 1 (Stx1) [18]. It was shown that the relative abundance of product ions was insensitive to the extent of reaction, consistent with parallel dissociation pathways involving a common reactant ion. Enhanced charge enrichment of the leaving subunit was observed at higher reaction temperatures, at least for the higher charge states investigated, providing additional evidence of inter-subunit proton transfer. Evidence of inter-subunits proton transfer within a protein homodimer was reported by Williams and coworkers [12]. These authors also showed that the degree of charge asymmetry observed for the dissociation of the dimers increased with the charge state of the complex and with increasing flexibility of the subunits. Based on these and other experimental studies, it has been proposed the asymmetric partitioning of charge observed for the dissociation of multiprotein complexes can result from unfolding of the leaving subunit, and concomitant increase in its gasphase basicity (and acidity), during dissociation [12, 18].

It may be possible to describe the asymmetric partitioning of charge by using simple electrostatic models in cases where charge-transfer between subunits is rapid compared with the loss of a subunit (i.e., the r-limiting step is the loss of subunit). Using the charged droplet model (CDM) of Ryce and Wyman, [26], which describes the charge distribution during fission of a spherical liquid drop into two offspring droplets, and treating multiprotein complexes and their subunits as liquid droplets, Smith and coworkers compared the lowest energy charge distribution calculated using CDM for the dissociation of the +14 ion of homotetramer streptavidin with experimental results [16]. Using sustained off-resonance irradiation collision-induced dissociation (SORI-CID) and Fourier-transform ion cyclotron resonance mass spectrometry (FT-ICR/MS) they showed that, upon activation, a single subunit was ejected at the +7 (major) and +6 (minor) charge states [16]. According to CDM, the +4 and +5 subunits charge states are energetically preferred for an early transition state (the two droplets touching) while the +6 charge state is preferred for a late transition state (infinite separation of droplets). It was argued that other factors, such as the conformational changes (unfolding) of the leaving subunit or, possibly, entropy effects, which are not accounted for within CDM, also influenced the partitioning of charge and lead to greater enrichment than predicted by CDM [16]. More recently, Heck and coworkers showed that CID of specific and nonspecific homodimer ions leads preferentially to monomer ions with an asymmetric distribution of charge [10]. According to CDM, the charge would be partitioned equally between the monomer ions. Thachuk and coworkers modeled the partitioning of charge between subunits in protein homodimers using the discretely charged ellipsoid model (DCEM) where ellipsoids of different sizes, shapes, and orientations were used to represent the protein subunits [27]. Considering only an early transition-state (i.e., ellipsoids touching), the authors demonstrated that, to within 10 to $15 \%$, the charge on the fission droplets is distributed according to their fractional surface area. The authors concluded that charge asymmetry of $>10$ to $15 \%$ for the dissociation of protein homodimers arises from differences in the surface area of the proteins, which could occur through unfolding or other conformational changes.

The above comparison between the charge asymmetry observed experimentally and predicted theoretically suggests that simple electrostatic models, such as CDM or DCEM, which do not include explicit consideration of protein/complex structure, underestimate the degree of charge asymmetry observed in the product ions. However, many of the reported MS/MS data for dissociation of multiprotein complexes, particularly for large, multisubunit complexes, were acquired under conditions where the complete isolation of just a single reactant ion (i.e., protonated complex with no adducts) could not be ascertained, and relatively high (compared with the reaction energy barrier) internal energies [10, 12-17]. At very high internal energies, which are required for prompt dissociation on the $\mu$ s time scale, the kinetics for different dissociation pathways are expected to be strongly influenced by entropy effects. It should also be noted that, the suitability of 
various electrostatic models have been assessed solely in terms of their ability to predict the charge partitioning between the product ions (i.e., dissociation pathways). The ability of theoretical models to account for the contribution of Coulombic repulsion energy to the dissociation activation energy has not been investigated.

The goal of the present work is to account for the influence of charge on the thermal dissociation pathways and energetics of multiply charged, multisubunit protein complexes in the gas phase, using two simplistic electrostatic models, CDM and the protein structure model (PSM), in which the higher order structure of the protein subunits is explicitly considered. The $\mathrm{B}_{5}$ homopentamers of Stx1 and Stx2 and the homotetramer streptavidin $\left(\mathrm{S}_{4}\right)$ served as model systems for this study. The pathways and Arrhenius parameters $\left(E_{a}, A\right)$ for the dissociation of protonated and deprotonated Stx1 $B_{5}$ ions and protonated $S t \times 2 B_{5}$ and $S_{4}$ ions, over a range of charge states, were determined using time-resolved blackbody infrared radiative dissociation (BIRD) experiments implemented with FT-ICR/MS. The experimental data were then compared with dissociation energies and the pathways predicted by CDM and PSM.

\section{Experimental}

\section{Proteins}

The Stx1 B subunit (38 $450 \mathrm{Da}$ ) was expressed in E. coli using a procedure described previously [28], purified to $>95 \%$ purity by affinity chromatography [29], dialyzed against $50 \mathrm{mM}$ ammonium acetate ( $\mathrm{pH} 7)$, and stored at $-20{ }^{\circ} \mathrm{C}$. A stock solution of the Stx1 B subunit at a concentration $1.15 \mathrm{mg} / \mathrm{mL}(150 \mu \mathrm{M})$ in $50 \mathrm{mM}$ ammonium acetate was prepared. A similar procedure was used for the preparation of the Stx2 B subunit (39 $075 \mathrm{Da}$ ) [28]. Streptavidin (53 $085 \mathrm{Da}$ ) was purchased from Roche Applied Science (Roche Diagnostics $\mathrm{GmbH}$, Laval, Canada), dialyzed against $50 \mathrm{mM}$ ammonium acetate $(\mathrm{pH} 7)$ and stored at $-20^{\circ} \mathrm{C}$. NanoES solutions were prepared by thawing the stock solutions at room temperature and diluting an aliquot to a subunit concentration of 10 to $20 \mu \mathrm{M}$ with aqueous ammonium acetate $(10 \mathrm{mM})$. Where lower complex charge states were desired in positive or negative mode, imidazole was added to nanoES solutions at a concentration of $\sim 1 \mathrm{mM}$. Imidazole is both a relatively strong acid and base in the gas phase (gas-phase basicity $=217 \mathrm{kcal} / \mathrm{mol}$ [30], gas-phase acidity $=343 \mathrm{kcal} / \mathrm{mol}$ [31], and can engage in proton transfer reactions with the protonated and deprotonated protein ions in the source, thereby reducing their charge states [32].

\section{Mass Spectrometry}

All experimental measurements were performed using a modified Apex II FT-ICR/MS (Bruker, Billerica, MA) equipped with a modified external nanoES ion source. Mass spectra were acquired at a magnetic field strength of $4.7 \mathrm{~T}$ or $9.4 \mathrm{~T}$. NanoES tips, with an o.d. of 4 to $7 \mu \mathrm{m}$, were pulled from aluminosilicate tubes ( $1 \mathrm{~mm}$ o.d., 0.68 $\mathrm{mm}$ i.d.) using a P-2000 micropipette puller (Sutter Instruments, Novato, CA). A platinum wire, inserted into the other end of the nanoES tip, was used to establish electrical contact with the nanoES solution. A potential of \pm 600 to $800 \mathrm{~V}$ was applied to the platinum wire in the nanoES tip to spray the solution. The tip was positioned 1 to $2 \mathrm{~mm}$ from a stainless steel sampling capillary using a microelectrode holder. Typical solution flow rates were 20 to $50 \mathrm{~nL} / \mathrm{min}$, depending on the diameter of the nanoES tip and the voltage used. Charged droplets and solvated ions emitted by the nanoES tip were introduced into the vacuum chamber of the mass spectrometer through a heated stainless steel sampling capillary $(0.43 \mathrm{~mm}$ i.d.) maintained at an external temperature of $66^{\circ} \mathrm{C}$. The gaseous ions sampled by the capillary $( \pm 48 \mathrm{~V})$ were transmitted through a skimmer $( \pm 4 \mathrm{~V})$ and accumulated for 2 to $5 \mathrm{~s}$ in an $\mathrm{rf}$ hexapole $\left( \pm 600 \mathrm{~V}_{p-p}\right)$. The ions were subsequently ejected from the hexapole and injected at $\pm 2700 \mathrm{~V}$ into the bore of the superconducting magnet, decelerated, and introduced into the ion cell. Two flexible heating blankets placed around the portion of the vacuum tube that surrounds the ion cell were used to control the temperature of the ion cell for the BIRD experiments. The typical base pressure for the instrument was $\sim 5 \times$ $10^{-10}$ mbar. Data acquisition was performed using the XMASS software (version 5.0, Bruker). The time-domain signals, consisting of the sum of 50 to 100 transients containing $128 \mathrm{~K}$ data points per transient, were subjected to one zero-fill before Fourier-transformation.

\section{Calculations}

Continuously and discretely charged droplet model. CDM, as developed by Ryce and Wyman [26], describes the fission of a spherical charged liquid drop into two droplets. The model assumes that the charge is distributed continuously and uniformly over the surface of the droplets and that charge-transfer between the droplets can occur at any distance. Within CDM, the transitionstate (TS) for droplet division is represented as two spheres with radii $r_{1}$ and $r_{2}$ and charge states $q_{1}$ and $q_{2}$, separated by a distance, $d$ (Figure 1a). According to the analytic expressions, which describe the minimum energy charge distribution, at $\mathrm{d}=0$ the charge is partitioned according to the ratio of surface areas of the droplets, while at $\mathrm{d}=\infty$ the charge is partitioned according to the ratio of the radii of the droplets. To apply CDM to the dissociation of a multisubunit complex, the product ions are assumed to be spherical in shape and have the same average density, such that the ratio of the radii is related to the ratio of the masses:

$$
\begin{aligned}
& \mathrm{q}_{1} / \mathrm{q}_{2}=\left(\mathrm{r}_{1} / \mathrm{r}_{2}\right)^{2}=\left(\mathrm{m}_{1} / \mathrm{m}_{2}\right)^{2 / 3} \quad \text { at } \mathrm{d}=0 \\
& \mathrm{q}_{1} / \mathrm{q}_{2}=\mathrm{r}_{1} / \mathrm{r}_{2}=\left(\mathrm{m}_{1} / \mathrm{m}_{2}\right)^{1 / 3} \quad \text { at } \mathrm{d}=\infty
\end{aligned}
$$


(a)

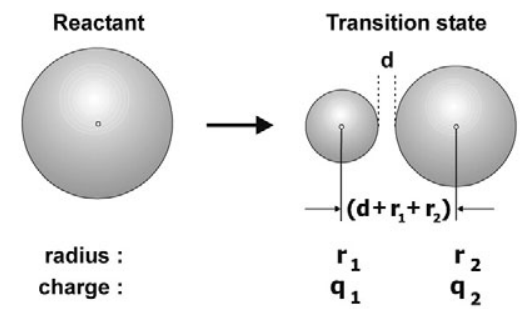

(b)

(c)
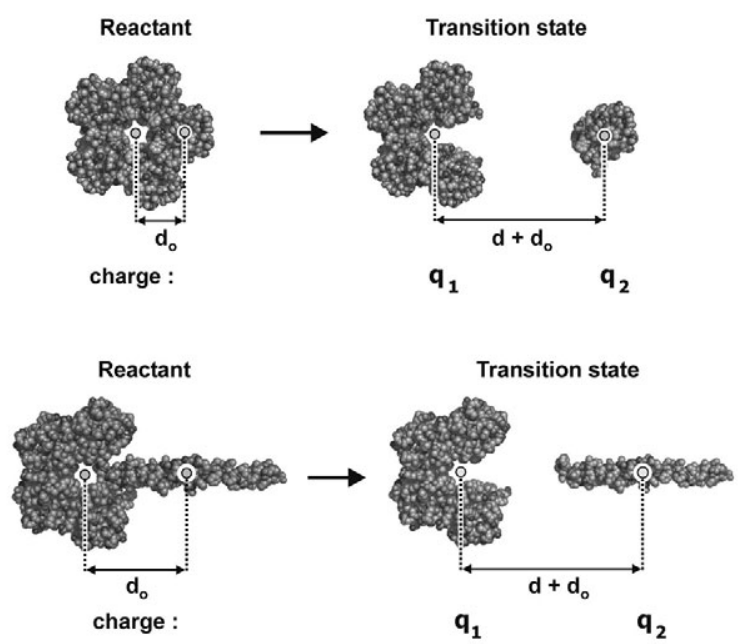

(d)

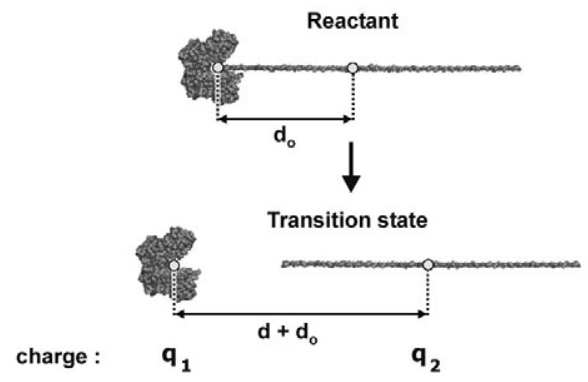

Figure 1. Electrostatic models: (a) charged droplet model (CDM), (b) protein structure model (PSM), (c) partially unfolded protein structure model (PU-PSM), and (d) fully unfolded protein structure model (FU-PSM).

To facilitate comparison between the experimental and theoretical results, a discrete form of CDM (i.e., DCDM) was also considered. In DCDM, discrete charges are placed on the surfaces of the two spheres. The charges are allowed to move freely over the surface of spheres but charge exchange between spheres is not allowed. The volumes (and radii) of both spheres were calculated from the mass of the dissociation products, assuming an average protein density of $1.41 \mathrm{~g} \cdot \mathrm{cm}^{-3}$ [33]. For a given protein complex charge state, the minimum electrostatic energy was calculated for each possible charge distribution using an energy minimization algorithm (Fletcher-Reeves) implemented in HyperChem version 7.51 (HyperCube Inc, Gainsville, FL).

Protein structure model. In the protein structure model, the three dimensional structure of the subunits/complex and, consequently, exact spatial position of the possible charge sites is explicitly considered. It is assumed that the charges reside exclusively on residues possessing side chains with the most favorable intrinsic gas-phase basicity (Arg, Lys and His) [30] or acidity (Asp and Glu) [34]. In the present study, the excess protons were positioned on the NH1 (Arg), NZ (Lys), and NE2 (His) atoms; alternatively protons were removed from the OD2 (Asp) and OE2 (Glu) atoms. The Coulombic repulsion energy $\left(E_{c}\right)$ of the protein complex (and the dissociative TS) was calculated using eq 2 :

$$
E=\sum_{\substack{i, j \\ i<j}} \frac{\mathrm{q}_{\mathrm{i}} \mathrm{q}_{\mathrm{j}}}{4 \pi \varepsilon_{0} \varepsilon \mathrm{r}_{\mathrm{i}, \mathrm{j}}}
$$

where $\mathrm{q}_{\mathrm{i}}$ and $\mathrm{q}_{\mathrm{j}}$ are the $i$ th and $j$ th charges, and $\mathrm{r}_{\mathrm{i}, \mathrm{j}}$ is the distance between the $i$ th and $j$ th charges. The dielectric constant, $\varepsilon$, was taken to be 1.0 for all of the calculations, unless otherwise specified. To find the minimum energy charge configuration (number and location within each subunit) a brute force approach was used, whereby the energies of all possible charge configurations were calculated and compared. All calculations were performed using a program that was written in-house.

In the simplest implementation of the protein structure model (referred to simply as PSM), the structure of the gaseous protein complex is assumed to be identical to crystal structure, as determined by X-ray analysis [35-37]. The exact locations of the acidic and basic residues are determined from the atomic coordinates taken from the crystal structure. Dissociation of the complex is assumed to proceed by the simple displacement of the one of the subunits from the complex, by a distance, $d$, with no other structural changes. This is illustrated for Stx $1 B_{5}$ in Figure $1 b$. To evaluate the influence of subunit unfolding on the product ion charge distribution, PSM was modified to consider cases where the leaving subunit was partially (PU-PSM) or fully unfolded (FU-PSM). The partially unfolded B subunit of Stx1 and Stx 2 was generated by maximizing the separation between the $\mathrm{N}$ - and the C-terminus of each subunit. This was accomplished by performing molecular dynamics (MD) simulations on the isolated, neutral subunit, initially in its native structure, at $300 \mathrm{~K}$ while imposing a distance constraint between the Nand the C-terminus. The distance constraint was gradually increased until no further increase in separation between the termini was observed, Figure 1c. The partially unfolded subunit of streptavidin was obtained by MD simulations carried out at $1500 \mathrm{~K}$ for 3 ps on the isolated neutral subunit with a distance constraint between the $\mathrm{N}$ - and the C-terminus of $50 \AA$. The very high simulation temperature was used to reduce the time required to partially unfold the subunit. Complete unfolding of a given subunit was achieved by building the subunit from the primary sequence using the Sequence Editor module in HyperChem. In the case of the 
B subunits of Stx1 and Stx2, the disulfide bond was omitted from the structure, Figure 1d. Where reported, surface areas of the protein subunits were calculated using Vega ZZ (version 2.0.4.1., University of Milan).

\section{Results and Discussion}

\section{NanoES Mass Spectra of B Subunits of Stx1 and Stx2, and of Streptavidin}

As described previously [38], the B subunits of Stx1 associate into a stable $B_{5}$ homopentamer in aqueous solution at neutral $\mathrm{pH}$ and subunit concentrations $>1$ $\mu \mathrm{M}$. The $\mathrm{B}_{5}$ complex is easily transferred to the gas phase by nanoES in both positive and negative ion modes. Shown in Figure 2a, b, c, and d are nanoES mass spectra acquired for aqueous solutions of $85 \mu \mathrm{M}$ Stx1 B and $25 \mathrm{mM}$ ammonium acetate $(\mathrm{pH} 7)$ in positive and negative ion modes. In positive mode, the pentamer is observed exclusively as the protonated ions, $\left(\mathrm{B}_{5}+\mathrm{nH}\right)^{n+} \equiv$ $\mathrm{B}_{5}^{n+}$ where $n=12$ to 14 (Figure 2a), while in negative ion mode the pentamer is observed predominantly as the deprotonated ions, $\left(\mathrm{B}_{5}-\mathrm{nH}\right)^{n-} \equiv \mathrm{B}_{5}^{n-}$ where $n=12$ to 14 (Figure $2 \mathrm{c}$ ). $\mathrm{B}_{5}^{n \pm}$ ions at lower charge states, as low as $n=9$, could be produced by adding imidazole to the nanoES solution (Figure $2 \mathrm{~b}$ and $\mathrm{d}$ ). It is important to note that the addition of imidazole to the solution did not have an observable effect on the stability of the pentamer in solution. Shown in Figure $2 \mathrm{e}$ is a nanoES mass spectrum acquired for aqueous solutions of $60 \mu \mathrm{M}$ Stx2 B and $25 \mathrm{mM}$ ammonium acetate $(\mathrm{pH} 7)$ in positive ion mode. Under these solution conditions, the B subunit of Stx 2 exists in multiple forms (i.e., $B_{2}, B_{3}, B_{4}$, and $B_{5}$ ), although the pentameric form is dominant (Figure 2e) [38]. The homopentamer of Stx2 is observed almost entirely as the protonated ions, $\left(\mathrm{B}_{5}+\mathrm{nH}\right)^{n+} \equiv \mathrm{B}_{5}^{n+}$ where $n=11$ to 13 . For a solution of $40 \mu \mathrm{M}$ streptavidin subunit and $25 \mathrm{mM}$ ammonium acetate ( $\mathrm{pH}$ 7) in positive ion mode, peaks corresponding to the protonated $S_{4}^{n+}$ tetramer ions, at $n=14$ to 16 , are observed, along with peaks corresponding to the protonated $S_{4}^{n+}$ ions with the attachment of one or two $\mathrm{KH}_{2} \mathrm{PO}_{4}$ adducts, Figure 2f.

\section{BIRD Mass Spectra of the $B_{5}^{\mathrm{n} \pm}$ and $S_{4}^{\mathrm{n}+}$ Ions}

Time-resolved BIRD experiments were performed on the protonated and deprotonated Stx $1 \mathrm{~B}_{5}^{n \pm}$ ions $(n=10$ to 14$)$ and protonated Stx $2 \mathrm{~B}_{5}^{n+}(n=12,13)$, and $S_{4}^{n+}$ ions $(n=14$ to 18$)$ at temperatures ranging from 120 to $190^{\circ} \mathrm{C}$. Illustrative BIRD spectra are shown in Figure 3, Figure 4, and Figure 5. In all cases, dissociation occurs predominantly by the loss of single subunit, which is ejected with a disproportionately large fraction (based on relative mass) of the total charge. Notably, the multimeric product ions [i.e., $\mathrm{B}_{4}^{(n-x) \pm}$ or $\mathrm{S}_{3}^{(n-x)+}$ ] do not undergo any measurable dissociation under these reac- (a)

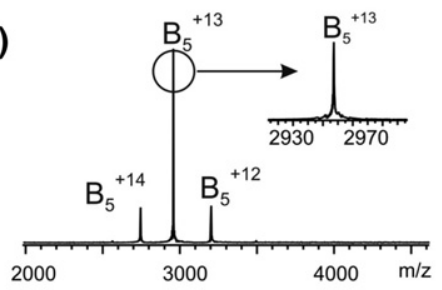

(c)

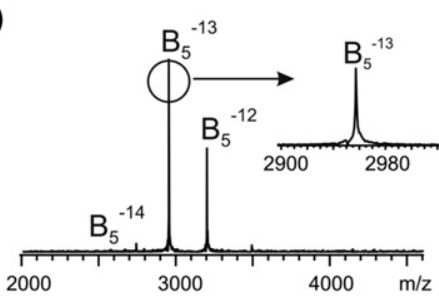

(e)

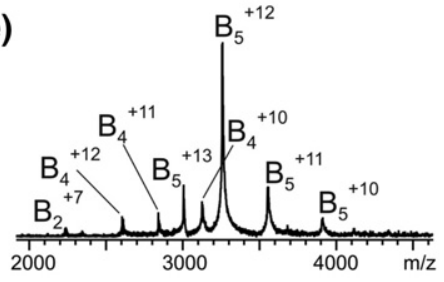

(b)

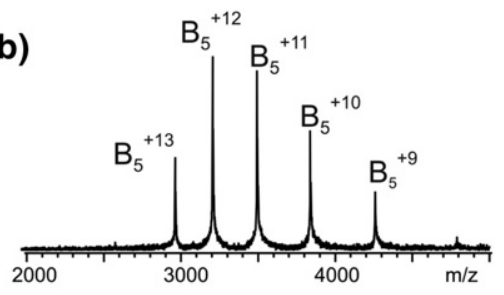

(d)
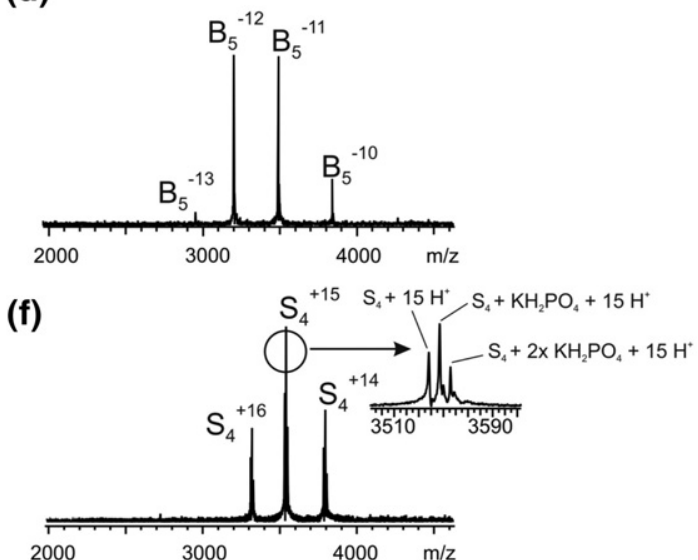

Figure 2. NanoES mass spectra of an aqueous solutions of (a) $85 \mu \mathrm{M}$ Stx1 B and $25 \mathrm{mM}$ ammonium acetate ( $\mathrm{pH} 7$ and $25^{\circ} \mathrm{C}$ ) obtained in positive ion mode; (b) same conditions as (a) plus the addition of $1 \mathrm{mM}$ imidazole; (c) $85 \mu \mathrm{M}$ Stx1 B and $25 \mathrm{mM}$ ammonium acetate ( $\mathrm{pH} 7$ and $25^{\circ} \mathrm{C}$ ) obtained in negative ion mode; (d) same conditions as (c) plus the addition of $1 \mathrm{mM}$ imidazole; (e) $60 \mu \mathrm{M}$ Stx2 B and $25 \mathrm{mM}$ ammonium acetate $\left(\mathrm{pH} 7\right.$ and $25^{\circ} \mathrm{C}$ ) obtained in positive ion mode; (f) $40 \mu \mathrm{M} \mathrm{S}{ }_{4}$ and 25 $\mathrm{mM}$ ammonium acetate ( $\mathrm{pH} 7$ and $25^{\circ} \mathrm{C}$ ) obtained in positive ion mode. 
(a)

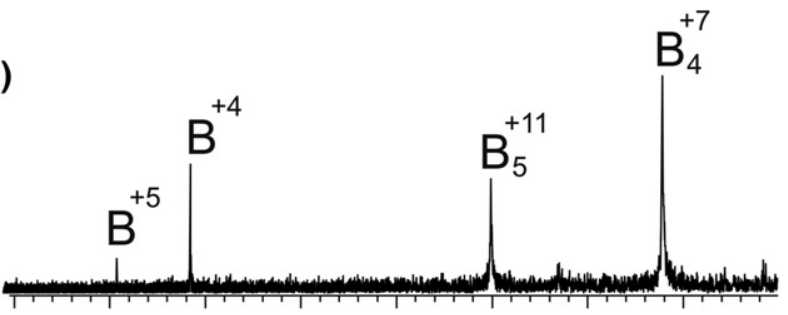

(b)

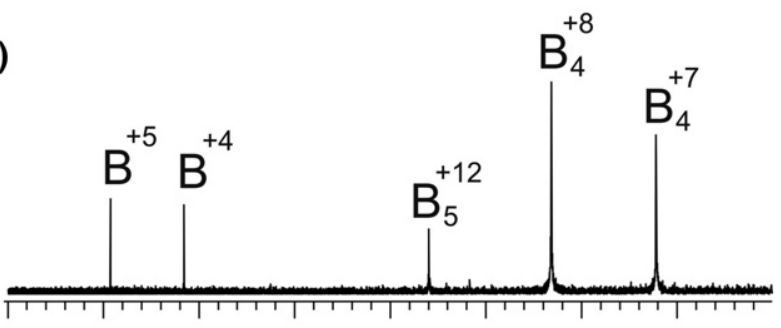

(c)

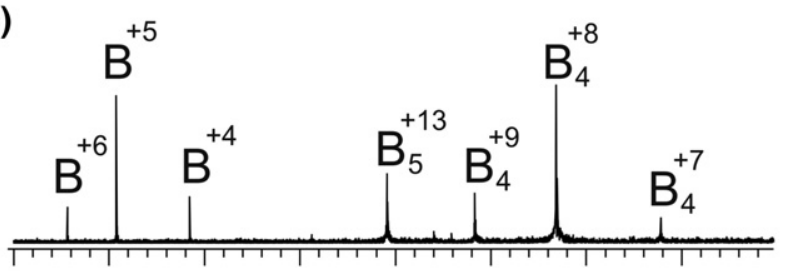

(d)

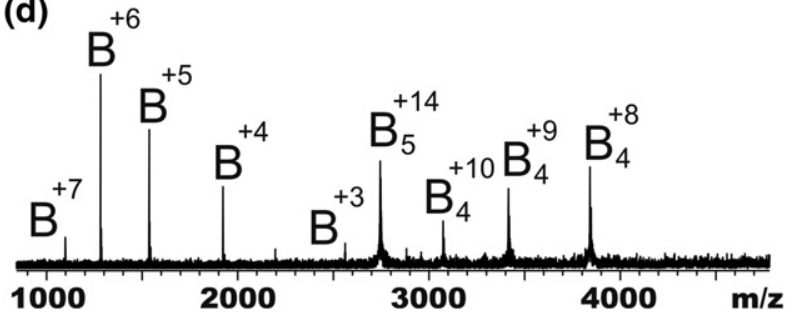

Figure 3. BIRD mass spectra of protonated Stx1 $\mathrm{B}_{5}^{n+}$ ions: (a) $\mathrm{B}_{5}^{11+}$ at a cell temperature of $166^{\circ} \mathrm{C}$ and a reaction time of $12 \mathrm{~s}$; (b) $\mathrm{B}_{5}^{12+}$ at $165^{\circ} \mathrm{C}$ and $2.5 \mathrm{~s}$; (c) $\mathrm{B}_{5}^{13+}$ at $165^{\circ} \mathrm{C}$ and $1.5 \mathrm{~s}$; (d) Stx1 $\mathrm{B}_{5}^{14+}$ at $143^{\circ} \mathrm{C}$ and $3.5 \mathrm{~s}$.

tion conditions. The absence of secondary dissociation indicates that the $\mathrm{B}_{4}^{(n-\mathrm{x}) \pm}$ or $\mathrm{S}_{3}^{(n-\mathrm{x})+}$ ions are kinetically (and, presumably, energetically) more stable at these temperatures than the $\mathrm{B}_{5}^{n \pm}$ or $\mathrm{S}_{4}^{n+}$ reactant ions.

It is interesting to compare the present BIRD results, obtained for the protonated Stx $1 \mathrm{~B}_{5}^{n+}$ ions produced from a solution at neutral $\mathrm{pH}$ with results obtained from an acidified ( $\mathrm{pH}$ 3.5) solution in which the pentamer undergoes partial disassembly [18]. Notably, the minor dissociation pathways leading to dimer/trimer ions, which was observed for ions produced from the acidified solution are absent from the BIRD spectra acquired in the present work. This result highlights the sensitivity of the dissociation pathways to the structure of the complex in solution.

Because the dissociation of the protein complex ions occurs via multiple dissociation pathways (with the exception of Stx1 B ${ }^{+10}$ ), it is useful to consider the average charge state of the ejected subunit. The absolute value of the weighted average subunit charge state $(A C S)$ is calculated using the following expression:

$$
A C S=\left|\Sigma f_{x} n_{x}\right|
$$

where $n_{x}$ represents the charge number of leaving subunit and $f_{x}$ represents its abundance, relative to the other subunit product ions. The magnitude of $f_{x}$ was determined from the measured intensities of the leaving subunit ions $\left(I_{x}\right)$. Because the ion signal in FT-ICR/MS is proportional to both the abundance and charge state of the ion, the measured intensities were normalized for charge state:

$$
f_{x}=\left(I_{x} / n_{x}\right) /\left(\Sigma I_{x} / n_{x}\right)
$$

Importantly, for a given complex, the $f_{x}$ (and $A C S$ ) values were found to be constant with respect to
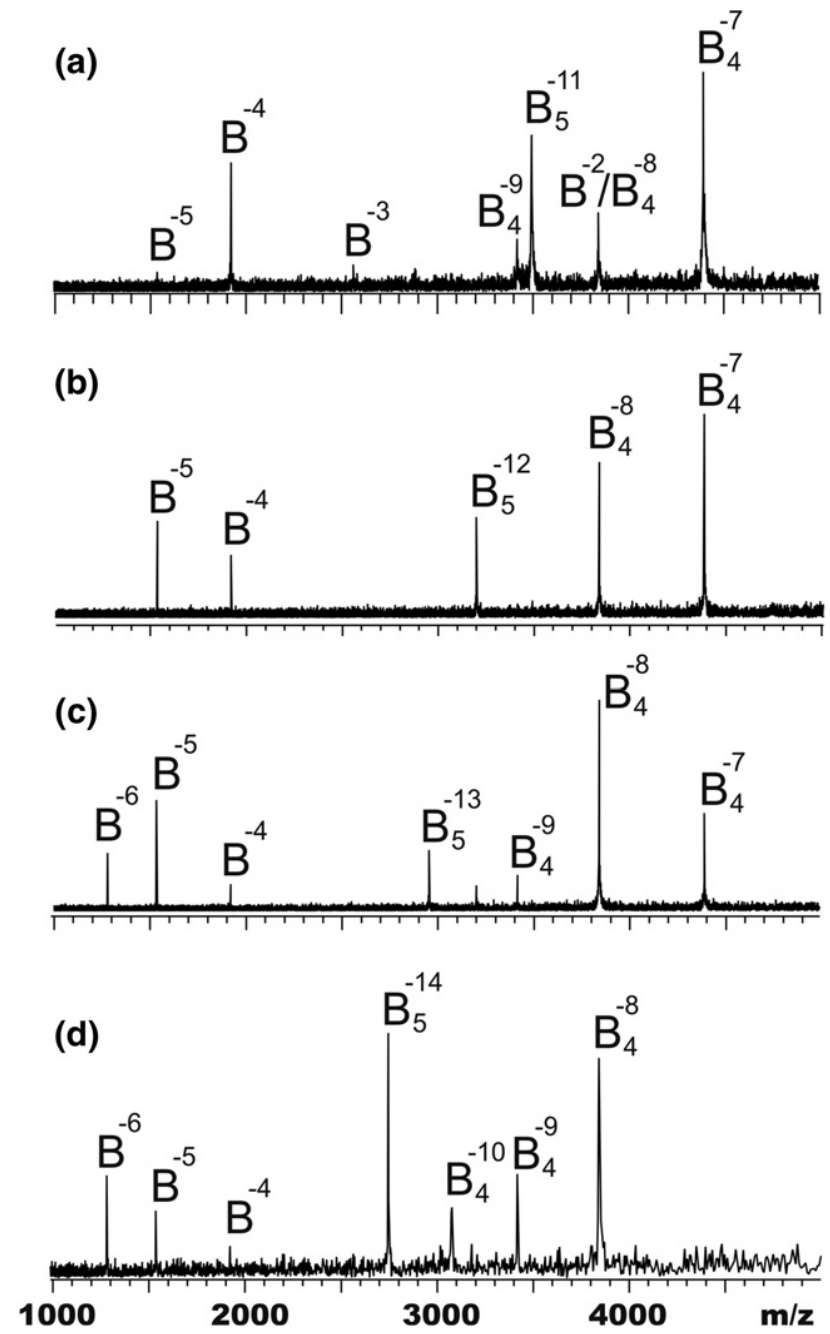

Figure 4. BIRD mass spectra of deprotonated Stx1 $\mathrm{B}_{5}^{n-}$ ions: (a) Stx $1 \mathrm{~B}_{5}^{11-}$, at a cell temperature of $165^{\circ} \mathrm{C}$ and a reaction time of $5 \mathrm{~s}$; (b) Stx $1 \mathrm{~B}_{5}^{12-}, 164{ }^{\circ} \mathrm{C}$, and $3.5 \mathrm{~s}$; (c) Stx $1 \mathrm{~B}_{5}^{13-}, 165^{\circ} \mathrm{C}$, and $1.2 \mathrm{~s}$; (d) Stx $1 \mathrm{~B}_{5}^{14-}, 143^{\circ} \mathrm{C}$, and $4 \mathrm{~s}$. 
(a)

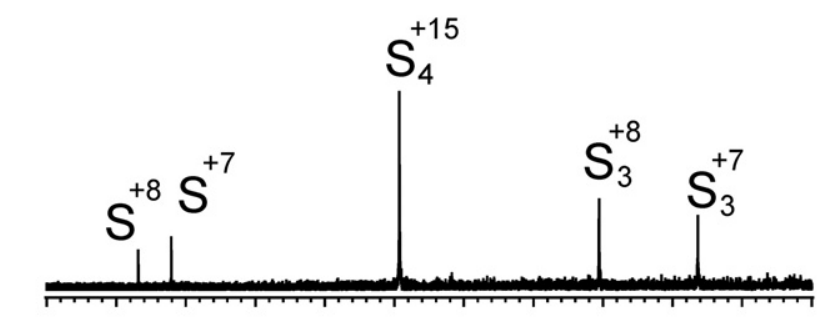

(b)

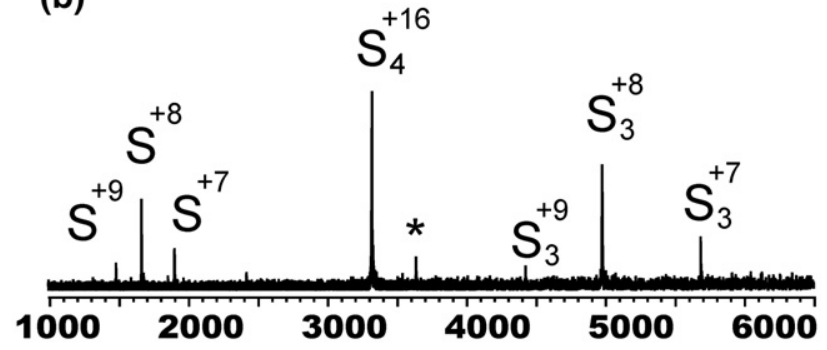

Figure 5. BIRD mass spectra of protonated $\mathrm{S}_{4}^{+n}$ ions: (a) $\mathrm{S}_{4}^{+15}$, at a cell temperature of $168^{\circ} \mathrm{C}$ and a reaction time of $1.8 \mathrm{~s}$; (b) $\mathrm{S}_{4}^{+16}$, $169^{\circ} \mathrm{C}$, and $1.6 \mathrm{~s}$. The peak labeled with an asterisk corresponds to the $\mathrm{S}_{4}^{+15}$ ion, which is produced from $\mathrm{S}_{4}^{+16}$ by charge-transfer.

reaction time. For example, shown in Figure 6 is a plot of the $f_{x}$ values, where $\mathrm{x}=-4,-5$, and -6 , determined for Stx1 $\mathrm{B}^{-13}$, versus reaction time. It can be seen that the slopes of the three curves are near zero $(0.007$ for $x=-6,0.006$ for $x=-5$, and 0.002 for $x=-4$ ). Similar results were obtained for the other protein complex ions investigated. These results, taken on their own, suggest that different product ion charge states are produced via parallel reactions, involving a single reactant ion. Interestingly, it was also found that the values of $f_{x}$ and $A C S$ are independent of the reaction temperature. More importantly, the ACS values were found to vary linearly with parent ion charge state (Figure 7). The average fractional charging of the leaving subunit, which corre-

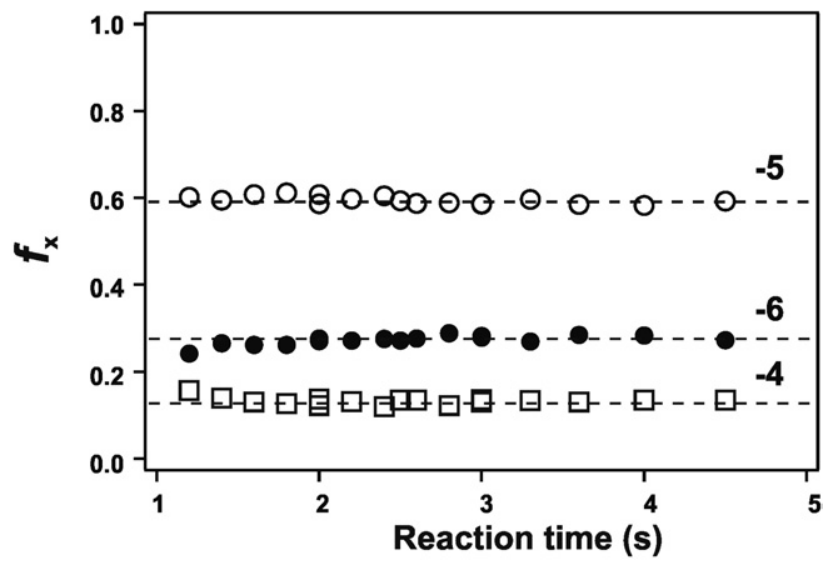

Figure 6. Plots of normalized abundance of the leaving subunit product ions $f_{x}$ versus reaction time measured for the Stx $\mathrm{B}_{5}^{-13}$ ion at a reaction temperature of $156{ }^{\circ} \mathrm{C}$.

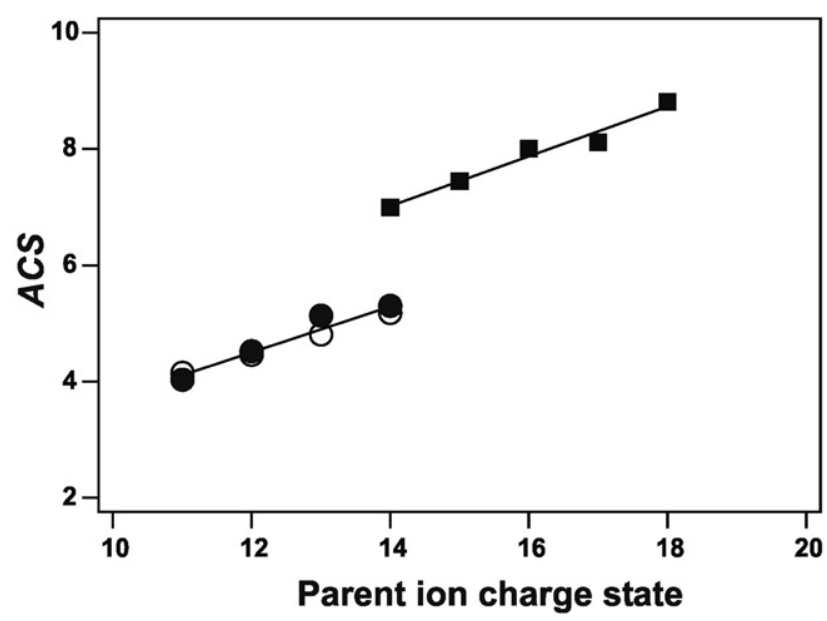

Figure 7. Plot of $A C S$ values as a function of the parent ion charge state for the Stx $1 \mathrm{~B}^{+n}$ (open circles) and $\mathrm{B}^{-n}$ (filled circles), and $\mathrm{S}_{4}^{+n}$ (filled squares) ions.

sponds to the ratio $A C S / n$, is $0.371 \pm 0.001$ for the Stx 1 $\mathrm{B}_{5}^{n \pm}$ ions, $0.346 \pm 0.001$ for the Stx2 $\mathrm{B}_{5}^{n+}$ ions, and $0.493 \pm$ 0.006 for the $S_{4}^{n+}$ ions.

The absence of an influence of complex charge state on the average fractional charging of the leaving subunit is a significant result as it implies that structures of the subunits within a complex are relatively insensitive to charge state, at least over the range of charge states investigated, vide infra. This result contrasts a significant charge state dependence observed by Williams and coworkers [12] for the dissociation of a homodimer. The absence of a charge state dependence in the present study may reflect the fact that the gaseous ions were produced from specific complexes present under native conditions. This was not the case in the aforementioned Williams' study. Additionally, the similarity between the ACS values for the protonated and deprotonated Stx $1 \mathrm{~B}_{5}^{n \pm}$ ions with the same number of charges suggests that, assuming proton transfer between subunits in the protonated complex is rapid compared with the rate of dissociation, proton transfer must be equally facile in the deprotonated complex.

Thermal Dissociation Kinetics for the $B_{5}^{\mathrm{n} \pm}$ and $S_{4}^{\mathrm{n}+}$ Ions

The thermal rate constants $(k)$ for the loss of a single subunit from the $\mathrm{B}_{5}^{n \pm}$ and $\mathrm{S}_{4}^{n+}$ ions at a specific temperature were determined from plots of the natural logarithm of the normalized abundance of the pentamer $\left(A_{R, n o r m}\right)$ versus reaction time:

$$
\ln A_{R, n o r m}=-k t
$$

The normalized abundance was calculated using the expression: 


$$
A_{R, \text { norm }}=I_{R} /\left(I_{R}+\Sigma I_{P}\right)
$$

where $I_{R}$ and $I_{P}$ correspond to the measured intensities of the reactant ion and all of the product ions, respectively. Shown in Figure 8a, b, and c are the kinetic plots obtained for Stx1 $\mathrm{B}_{5}^{+12}, \mathrm{~B}_{5}^{+14}, \mathrm{~B}_{5}^{-12}$ ions at the reaction temperatures indicated. The kinetic plots obtained at the higher charge states, i.e., $+13,14$, are reasonably linear at the temperatures investigated, consistent with a single dominant structure for the $\mathrm{B}_{5}^{n \pm}$ ions. In contrast, the plots obtained for the lower charge state ions appear to be made up of two components, a "fast" and a "slow" component. Similar nonlinear kinetic plots were observed for the Stx2 $\mathrm{B}_{5}^{+n}$ ions investigated [38], and for the lower charge states of the $S_{4}^{+n}$ ions $(n=14,15)$ considered (Figure $8 \mathrm{~d}$ ). There are a number of possible explanations for the nonlinearity of first-order kinetic plots and these have been discussed recently [39]. Possibly, some of the $\mathrm{B}_{5}^{n \pm}$ and $\mathrm{S}_{4}^{+n}$ ions consist of multiple, non-interconverting, structures with distinct dissociation rate constants. Alternatively, thermallyinduced changes in the conformation of the complex, leading to a kinetically more stable structure, may occur over the course of the reaction and thereby alter the rate of dissociation [39]. The latter explanation seems unlikely since conformational changes would be expected to lead to a gradual decrease in reactivity rather than the abrupt changes that are observed, particularly at the lower reaction temperatures. Interestingly, the temperature-dependence of the rate constants determined for fast and slow components is similar. These results strongly suggest that the differences in reactivity are primarily entropic in nature, although the origin of this effect is not known. The differences in $\Delta S^{\ddagger}$ values for the fast and slow components (i.e., $\Delta \Delta S^{\ddagger}$ ) have been estimated to be in the range of 2 to $7 \mathrm{cal} / \mathrm{mol} \mathrm{K}$. Regardless of the nature of the entropic effect, it is important to note that it does not influence how charge is distributed between product ions.

The nonlinear kinetic plots complicated the determination of the dissociation rate constants at the lower charge states investigated. Estimates of the dissociation rate constants were obtained by applying a linear least-squares fit to the fast component of the kinetic plots. It should be noted that the rate constants measured for the Stx $1 B_{5}^{+11}$ ion at the lowest reaction temperatures investigated were found to differ from the values reported in the previous BIRD study [18]. The discrepancies are attributed to the low abundance of the $\mathrm{B}_{5}^{+11}$ ion in the previous study. The abundance of the $\mathrm{B}_{5}^{+11}$ ion was significantly enhanced in the present work, due to the implementation of the new methodology for producing lower charge state ions, which involves the addition of imidazole to the nanoES solution. The higher signal intensities allowed for more reliable kinetic measurements.
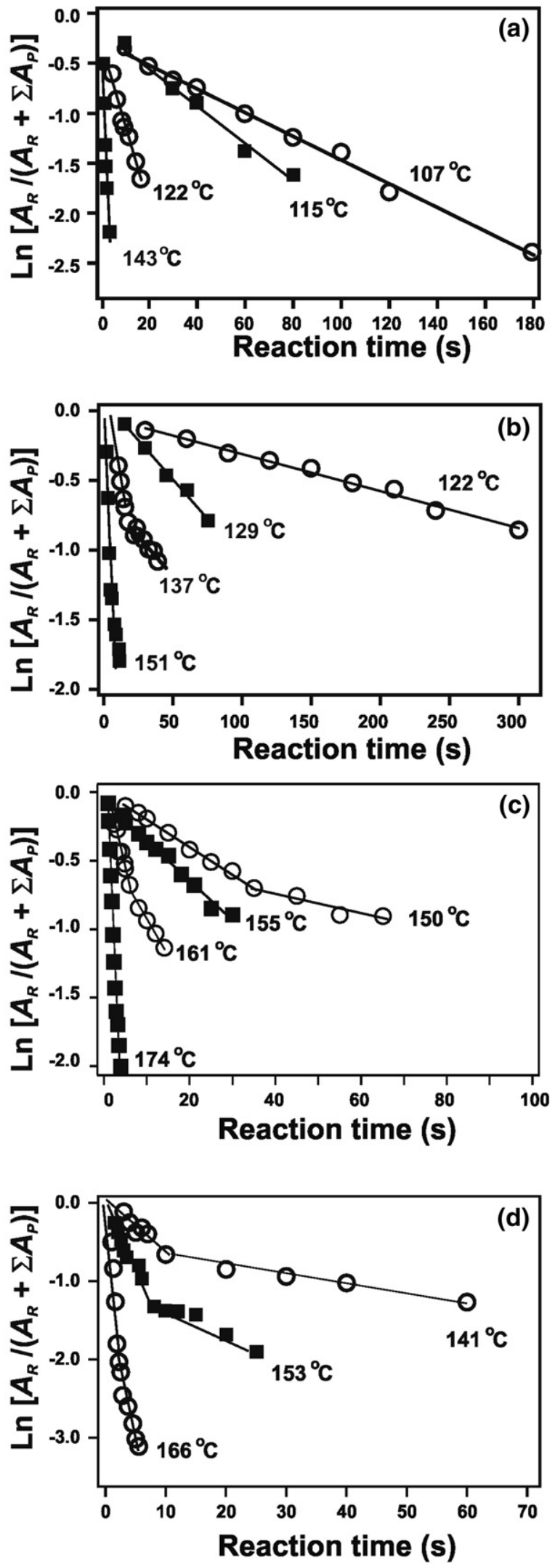

Figure 8. BIRD kinetic data for the loss of a subunit from the Stx1 $\mathrm{B}_{5}^{n \pm}$ and $\mathrm{S}_{4}^{+n}$ ions. The natural logarithm of the normalized abundance of the reactant ions is plotted versus reaction time at the temperatures indicated for (a) $\mathrm{B}_{5}^{+14}$, (b) $\mathrm{B}_{5}^{+12}$, (c) $\mathrm{B}_{5}^{-12}$, and (d) $\mathrm{S}_{4}^{+14}$. 


\section{Arrhenius Activation Parameters for Dissociation of the $B_{5}^{\mathrm{n} \pm}$ and $S_{4}^{\mathrm{n}+}$ Ions}

From the temperature dependence of the rate constants determined for the subunit loss from the "fast" reacting species, Arrhenius plots were constructed. The Arrhenius plots for the Stx $1 B_{5}^{n \pm}$ ions are shown in Figure 9a; plots for the $\mathrm{Stx} 2 \mathrm{~B}_{5}^{n+}$ and $\mathrm{S}_{4}^{+n}$ ions are shown in Figure $9 \mathrm{~b}$. It should be noted that the plots for the Stx $1 \mathrm{~B}_{5}^{n+}$ ions at charge states $n=12$ to 14 were reported previously [18].
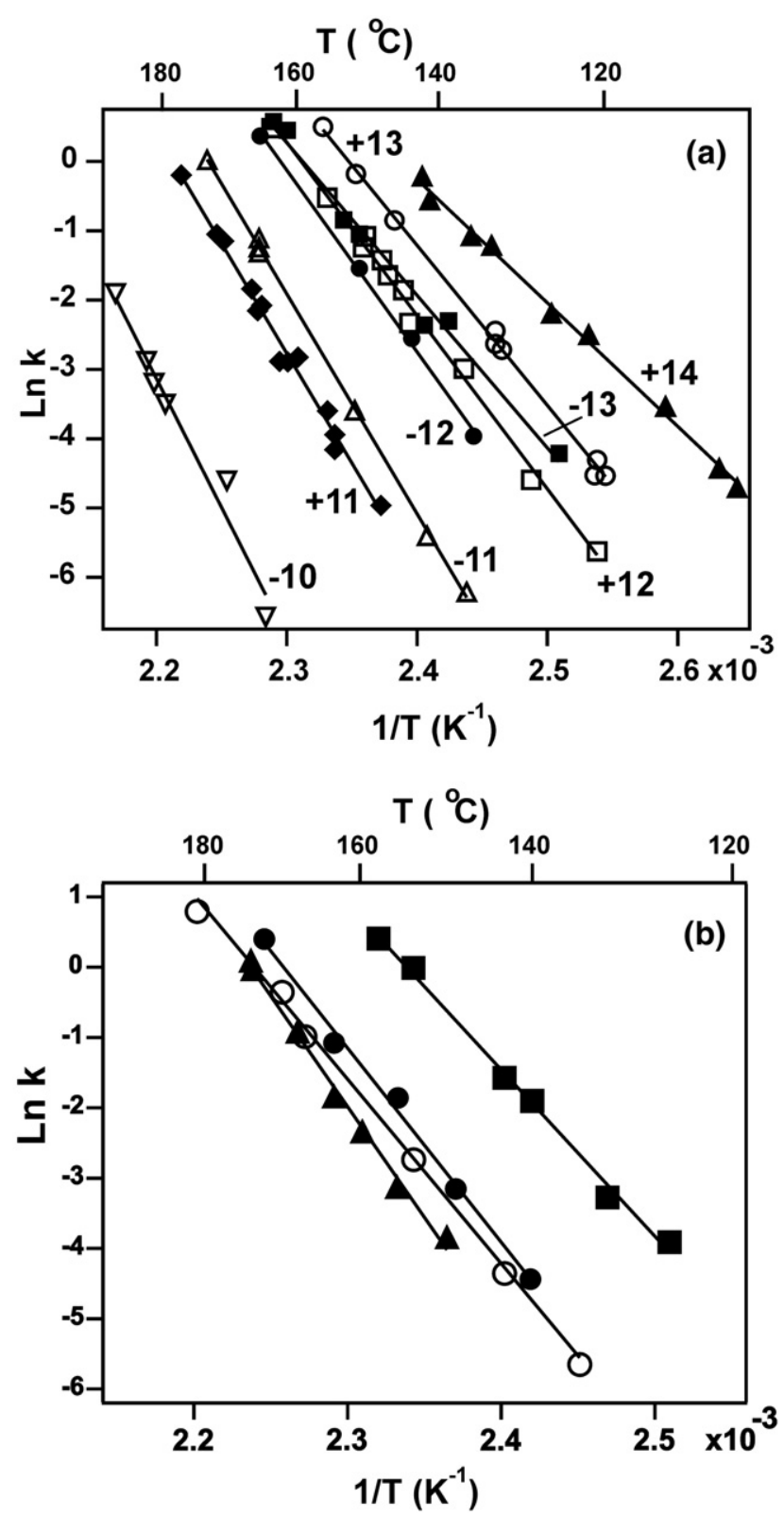

Figure 9. (a) Arrhenius plots for the loss of a subunit from of the protonated and deprotonated Stx $1 \mathrm{~B}_{5}^{n \pm}$ ions, at $n=+11$ (filled diamond), +12 (open square), +13 (open circle), +14 (filled triangle), -10 (inverted open triangle), -11 (open triangle), -12 (filled circle), -13 (filled square). (b) Arrhenius plots for the loss of a subunit from of the protonated Stx2 $\mathrm{B}_{5}^{n+}$ ions, at $n=+12$ (open circle), +13 (filled square), and $\mathrm{S}_{4}^{+n}$ ions, at $n=+14$ (filled triangle), +15 (filled circle).
Despite the uncertainty associated with the rate constants determined for the lower charge states, the Arrhenius plots for all of the ions exhibit good linearity over the range of temperatures investigated. The Arrhenius activation energy $\left(E_{a}\right)$ and pre-exponential factor (A) were determined from the slope and y-intercept, respectively, of the plots and the values are listed in Table 1. Also listed are the $\Delta S^{\ddagger}$ values, which were calculated from the corresponding A-factors at $142{ }^{\circ} \mathrm{C}$.

From a comparison of Arrhenius plots, clearly the gas-phase stabilities of the complexes are influenced by charge state. Over the range of temperatures investigated, the kinetic stabilities of the complexes decrease with increasing charge state. The trend in kinetic stability mirrors the trend in the $E_{a}$ and $A$ values. The $E_{a}$ values for the Stx $1 B_{5}^{n+}$ ions range from $63(+11)$ to 35 $\mathrm{kcal} / \mathrm{mol}(+14)$ and from $74(-10)$ to $44 \mathrm{kcal} / \mathrm{mol}(-13)$ for the Stx $1 \mathrm{~B}_{5}^{n-}$ ions. The A-factors range from $10^{31}$ $(+11)$ to $10^{19} \mathrm{~s}^{-1}(+14)$ for the $\mathrm{B}_{5}^{n+}$ ions and from $10^{34}$ $(-10)$ to $10^{22} \mathrm{~s}^{-1}(-13)$ for the $\mathrm{B}_{5}^{n-}$ ions. A similar trend in the parameters is also found for the Stx2 $\mathrm{B}_{5}^{n+}$ and $\mathrm{S}_{4}^{n+}$ ions (Table 1). It is interesting to note that the dissociation $E_{a}$ values for protonated and deprotonated Stx1 $\mathrm{B}_{5}^{n \pm}$ ions with the same number of charges are identical, within experimental error. This result represents the first reported example where the energetic stability of a gaseous multiprotein complex is found to be insensitive to the nature and location of the charged residues. Instead, the dominant effect of the multiple charges on the dissociation $\mathrm{E}_{\mathrm{a}}$ values appears to be due to the long range repulsion between charged groups, both within and between subunits. While the nature and location of the charged residues do not significantly influence the $E_{a}$ values for the Stx $1 B_{5}^{n \pm}$ ions, they do influence the magnitude of the A-factors (and $\Delta S^{\ddagger}$ values), with somewhat smaller A-factors observed for the Stx $1 B_{5}^{-12}$ and $\mathrm{B}_{5}^{-13}$ ions (compared with $\mathrm{B}_{5}^{+12}$ and $\mathrm{B}_{5}^{+13}$ ), but a larger A-factor for $\mathrm{B}_{5}^{-11}$ (compared with $\mathrm{B}_{5}^{+11}$ ).

\section{Modeling of the Product Ion Charge Distribution for the $B_{5}^{\mathrm{n} \pm}$ and $S_{4}^{\mathrm{n}+}$ Ions}

As described above, the time-resolved BIRD data suggest that the distribution of product ions from the dissociation of multiply charged multiprotein complexes originate from parallel dissociation pathways involving a single reactant, at least for the higher charge states investigated. Consequently, the relative abundance of product ions (and $A C S$ ) reflects the relative dissociation rate constants or free energies of activation $\left(\Delta G^{\ddagger}\right)$. According to transition-state theory, the ratio of charge-normalized abundance $\left(I_{x} / n=A_{x}\right)$ of the leaving subunit product ions with $\mathrm{x}$ and $\mathrm{x}+1$ charges produced from a single reactant is given by the following expression:

$$
A_{\mathrm{x}} / A_{\mathrm{x}+1}=k_{\mathrm{x}} / k_{\mathrm{x}+1}=\exp \left(\left(\Delta \mathrm{G}_{\mathrm{x}+1}^{\ddagger}-\Delta \mathrm{G}_{\mathrm{x}}^{\ddagger}\right) / \mathrm{RT}\right)
$$


Table 1. Arrhenius activation parameters $\left(E_{a}, A\right)$ and entropy of activation $\left(\Delta S^{\ddagger}\right)$ for the loss of a subunit from the protonated and deprotonated Stx1 $B_{5}^{\mathrm{n} \pm}$, protonated Stx2 $\mathrm{B}_{5}^{\mathrm{n}+}$, and $\mathrm{S}_{4}^{\mathrm{n}+}$ ions

\begin{tabular}{llccc}
\hline Complex & Major products & $\mathrm{E}_{\mathrm{a}}(\mathrm{kcal} / \mathrm{mol})^{\mathrm{a}}$ & $\mathrm{A}\left(\mathrm{s}^{-1}\right)^{\mathrm{a}}$ & $\Delta \mathrm{S}^{\ddagger}(\mathrm{cal} / \mathrm{mol} \cdot \mathrm{K})^{\mathrm{b}}$ \\
\hline \hline Stx1 $\mathrm{B}_{5}^{+11}$ & $\mathrm{~B}^{+4} / \mathrm{B}_{4}^{+7}$ & $63.0 \pm 2.1$ & $10^{30.5 \pm 1.0}$ & 78 \\
Stx1 $\mathrm{B}_{5}^{+12}$ & $\mathrm{~B}^{+4} / \mathrm{B}_{4}^{+8}, \mathrm{~B}^{+5} / \mathrm{B}_{4}^{+7}$ & $51.8 \pm 1.1^{\mathrm{c}}$ & $10^{26.2 \pm 0.6 \mathrm{c}}$ & 59 \\
Stx1 $\mathrm{B}_{5}^{+13}$ & $\mathrm{~B}^{+5} / \mathrm{B}_{4}^{+8}$ & $46.2 \pm 1.1^{\mathrm{c}}$ & $10^{23.0 \pm 0.6 \mathrm{c}}$ & 44 \\
Stx1 $\mathrm{B}_{5}^{+14}$ & $\mathrm{~B}^{+6} / \mathrm{B}_{4}^{+8}$ & $35.4 \pm 0.9^{\mathrm{c}}$ & $10^{18.5 \pm 0.4 \mathrm{c}}$ & 23 \\
Stx1 $\mathrm{B}_{4}^{-10}$ & $\mathrm{~B}^{-3} / \mathrm{B}_{4}^{-7}, \mathrm{~B}^{-4} / \mathrm{B}_{4}^{-6}$ & $73.8 \pm 6.7$ & $10^{34.2 \pm 3.3}$ & $10^{30.9 \pm 0.5}$ \\
Stx1 $\mathrm{B}_{5}^{-11}$ & $\mathrm{~B}^{-4} / \mathrm{B}_{4}^{-7}$ & $63.0 \pm 1.0$ & $10^{26.2 \pm 0.8}$ & 85 \\
Stx1 $\mathrm{B}_{5}^{-12}$ & $\mathrm{~B}^{-5} / \mathrm{B}_{4}^{-7}$ & $52.1 \pm 1.5$ & $10^{22.2 \pm 1.1}$ & 50 \\
Stx1 $\mathrm{B}_{5}^{-13}$ & $\mathrm{~B}^{-5} / \mathrm{B}_{4}^{-8}$ & $43.8 \pm 2.2$ & $10^{25.6 \pm 1.0 d}$ & 40 \\
Stx2 $\mathrm{B}_{5}^{+12}$ & $\mathrm{~B}^{+4} / \mathrm{B}_{4}^{+8}$ & $52.2 \pm 2.1^{\mathrm{d}}$ & $10^{24.1 \pm 0.8 \mathrm{~d}}$ & 56 \\
Stx2 $\mathrm{B}_{5}^{+13}$ & $\mathrm{~B}^{+4} / \mathrm{B}_{4}^{+9}, \mathrm{~B}^{+5} / \mathrm{B}_{4}^{+8}$ & $47.1 \pm 1.6^{\mathrm{d}}$ & $10^{30.6 \pm 1.1}$ & 49 \\
$\mathrm{~S}_{4}^{+14}$ & $\mathrm{~S}^{+7} / \mathrm{S}_{3}^{++7}$ & $62.6 \pm 2.2$ & $10^{27.1 \pm 2.2}$ & 79 \\
$\mathrm{~S}_{4}^{+15}$ & $\mathrm{~S}^{+7} / \mathrm{S}_{3}^{+8}, \mathrm{~S}^{+8} / \mathrm{S}_{3}^{+7}$ & $54.9 \pm 2.3$ & & 63 \\
\hline
\end{tabular}

aThe reported errors are one standard deviation.

bValues calculated at $415 \mathrm{~K}$ from the corresponding A-factors.

${ }^{\mathrm{c}}$ Arrhenius parameters taken from reference [18].

${ }^{\mathrm{d}}$ Arrhenius parameters taken from reference [38].

If the $\Delta G^{\ddagger}$ values for the different pathways are known (or the differences in $\Delta \mathrm{G}^{\ddagger}$ are known), the relative abundance of the product ions produced from a single reactant ion can be predicted. Due to the uncertainty in the reaction coordinate for the dissociation reactions, it is not possible to estimate theoretically the entropy of activation $\left(\Delta S^{\ddagger}\right)$ for a given pathway. However, if the $\Delta S^{\ddagger}$ values for different pathways are similar, i.e., $\Delta S_{x}^{\ddagger} \approx \Delta S_{x+1}^{\ddagger}$, then the relative abundance of the product ions will reflect only the relative magnitude of the enthalpy of activation $\left(\Delta \mathrm{H}^{\ddagger}\right)$ or $\mathrm{E}_{\mathrm{a}}$ values, with the lowest energy pathway leading to the most abundant product ions:

$$
\begin{aligned}
A_{\mathrm{x}} / A_{\mathrm{x}+1} & =k_{\mathrm{x}} / k_{\mathrm{x}+1} \approx \exp \left(\Delta \mathrm{H}_{\mathrm{x}+1}^{\ddagger}-\Delta \mathrm{H}_{\mathrm{x}}^{\ddagger}\right) \\
& =\exp \left(\mathrm{E}_{\mathrm{a}, \mathrm{x}+1}-\mathrm{E}_{\mathrm{a}, \mathrm{x}}\right)
\end{aligned}
$$

Shown in Figure 10 is a hypothetical energy diagram for the dissociation of a multiply charged homopentamer into charged monomer and tetramer ions. At a given charge state, the dissociation $\mathrm{E}_{\mathrm{a}}$ can be described as the sum of two terms, the intrinsic activation energy $\left(E_{a, o}\right)$, which represents the stabilizing interaction energy and can be thought of as the $E_{a}$ of the gaseous complex in the absence of Coulombic repulsion, and an electrostatic term $\left(E_{c}^{\ddagger}-E_{c}^{o}\right)$, which is the difference in Coulombic repulsion energy in the reactant $\left(\mathrm{E}_{\mathrm{c}}^{\mathrm{o}}\right)$ and the transition-state $\left(E_{c}^{\ddagger}\right)$, eq 9:

$$
\mathrm{E}_{\mathrm{a}}=\mathrm{E}_{\mathrm{a}, \mathrm{o}}+\left(\mathrm{E}_{\mathrm{c}}^{\ddagger}-\mathrm{E}_{\mathrm{c}}^{o}\right)
$$

For parallel reactions involving a single parent ion, the $E_{a, o}$ and $E_{c}^{o}$ terms will be equivalent and the difference in $E_{a}$ values for the different pathways will reflect the difference in the $\mathrm{E}_{\mathrm{c}}^{\ddagger}$ values. Two approaches, $\mathrm{CDM}$ and PSM, to evaluate the $E_{c}^{\ddagger}$ values were employed. Below is an analysis of product ion charge distributions predicted by the different models.
Charged droplet model (CDM). The leaving subunit charge state(s) corresponding to the lowest energy charge distribution, as predicted by CDM and DCDM, was calculated for an early TS, corresponding to two spheres touching (i.e., $\mathrm{d}=0$ ) and a late $T S$, corresponding to infinite separation $(d=\infty)$. The lowest energy leaving subunit charge states predicted by CDM and DCDM along with dominant subunit charge states determined from the BIRD spectra are listed in Table 2.

Comparison of the experimental and theoretical results reveals several interesting features. First, DCDM predicts somewhat higher subunit charge states compared with CDM. A similar result was shown previously by Thachuk and was explained in terms of the discreetness of the charge and the configurational restrictions imposed by the location of charge sites [27]. It

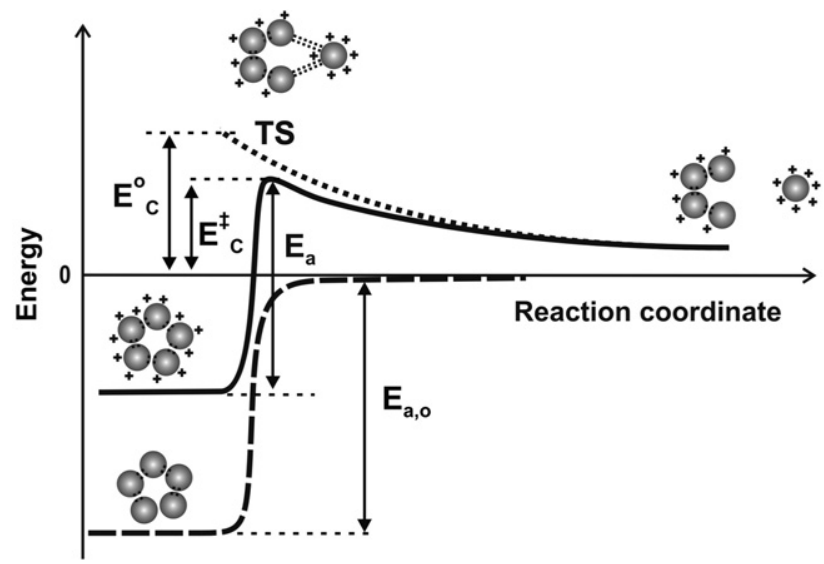

Figure 10. Hypothetical energy diagram for the dissociation of a multiply charge homopentameric complex into monomer and tetramer ions. $E_{a}$ is the dissociation activation energy for the complex at a given charge state, $\mathrm{E}_{\mathrm{a}, \mathrm{o}}$ is the intrinsic activation energy $\left(E_{a, o}\right)$, which represents the stabilizing interaction energy and $\mathrm{E}_{\mathrm{c}}^{\mathrm{o}}$ and $\mathrm{E}_{\mathrm{c}}^{\ddagger}$ represent the Coulombic repulsion energy in the reactant and the transition-state, respectively. 
Table 2. Comparison of the most abundant leaving subunit charge state(s) observed for the dissociation of the Stx $1 B_{5}^{ \pm}$, Stx 2 B ${ }_{5}^{+}$, and $\mathrm{S}_{4}^{\mathrm{n}+}$ ions and the lowest energy subunit charge state(s) predicted from electrostatic models: charged droplet model (CDM), discretely charged droplet model (DCDM), protein structure model (PSM), partially unfolded subunit PSM (PU-PSM), and fully unfolded PSM (FU-PSM). Theoretical charge states are reported for a very early $(\mathrm{d}=0)$ and a very late $(\mathrm{d}=\infty)$ transition state $\mathrm{a}^{\mathrm{a}}$

\begin{tabular}{|c|c|c|c|c|c|c|c|c|c|c|}
\hline \multirow[b]{2}{*}{ Reactant } & \multirow[b]{2}{*}{ Exp } & \multicolumn{2}{|c|}{$\mathrm{CDM}^{\mathrm{b}}$} & \multicolumn{2}{|c|}{ DCDM } & \multicolumn{2}{|c|}{ PSM } & \multicolumn{2}{|c|}{ PU-PSM } & \multirow{2}{*}{$\begin{array}{l}\text { FU-PSM } \\
d=0\end{array}$} \\
\hline & & $\mathrm{d}=0$ & $d=\infty$ & $\mathrm{d}=0$ & $d=\infty$ & $\mathrm{d}=0$ & $d=\infty$ & $\mathrm{d}=0$ & $d=\infty$ & \\
\hline Stx1 $B_{5}^{-10}$ & 4 & $2.8(3)$ & $3.9(4)$ & 3 & 4 & 2,3 & 4 & 3 & 4 & 6 \\
\hline Stx1 $B_{5}^{ \pm 11}$ & 4 & $3.1(4)$ & $4.3(4)$ & 3,4 & 4,5 & 3 & 4 & 3 & 4,5 & 6 \\
\hline Stx $1 B_{5}^{ \pm 12}$ & 4,5 & 3.4 (4) & $4.6(4,5)$ & 4 & 5 & 3 & 5 & 3,4 & 5 & 6,7 \\
\hline Stx $1 B_{5}^{ \pm 13}$ & 5 & 3.7 (4) & 5.0 & 4,5 & 5 & 3,4 & 5 & 4 & 5 & 7 \\
\hline Stx $1 B_{5}^{ \pm 14}$ & 6 & 4.0 & $5.4(6)$ & 5 & 6 & 4 & 5 & 4 & 6 & 8 \\
\hline Stx $2 B_{5}^{+12}$ & 4 & $3.4(4)$ & $4.6(5)$ & 4 & 5 & 2,3 & 4 & 3,4 & 5 & 6,7 \\
\hline Stx $2 B_{5}^{+13}$ & 4,5 & $3.7(4,5)$ & 5.0 & 4,5 & 5 & 3 & 5 & 4 & 5,6 & 7 \\
\hline $\mathrm{S}_{4}^{+14}$ & 7 & 4.6 & 5.7 & 4,5 & 6 & 3,4 & 6 & 7 & 7 & 8 \\
\hline $\mathrm{S}_{4}^{+15}$ & 7,8 & 4.9 & 6.1 & 5 & 6 & 3,4 & 6 & 7 & 7 & 8,9 \\
\hline $\mathrm{S}_{4}^{+18}$ & 9 & 5.8 & 7.4 & 7 & 8 & 4,5 & 7 & 8,9 & 8,9 & 9,10 \\
\hline
\end{tabular}

aWere multiple charge states are reported for a given electrostatic model, the calculated energies are within $2.5 \mathrm{kcal} / \mathrm{mole}$ of the lowest value.

balues in brackets represent lowest energy integer charge states.

should be noted, however, that the energetically preferred whole number charge state predicted by CDM matches DCDM exactly. Secondly, and more importantly, CDM/DCDM account for the dominant charge state(s) on the leaving subunit observed for the dissociation of the $\mathrm{B}_{5}^{n \pm}$ ions of Stx1 and Stx2. To our knowledge, this is the first example where CDM has been shown to correctly describe the dominant product ion charge states for the dissociation of a multiprotein complex. For the Stx $2 \mathrm{~B}_{5}^{n+}$ ions an early TS is required $(d=0)$ to account for observed charge states, while for the Stx $1 \mathrm{~B}_{5}^{n \pm}$ ions a late TS $(\mathrm{d}=\infty)$ is necessary. A very late TS has no physical meaning since the probability for proton transfer between subunits becomes infinitely small at large inter-subunit distances. A recent theoretical study by Kebarle and coworkers on the reaction coordinate for proton transfer between doubly charged diaminoalkanes and ammonia suggested a TS distance of $\sim 5 \AA$ for proton transfer [40]. To establish the minimum $\mathrm{d}$ necessary to account for the dominant observed product charge states for the Stx $1 \mathrm{~B}_{5}^{n \pm}$ ions, minimum energy charge configurations were calculated using DCDM for $\mathrm{d}$ values ranging from 0 to $200 \AA$ and also for $\mathrm{d}=\infty$ (Figure 11). These calculations reveal that the major product ion charge states observed experimentally are predicted at relative short and more realistic distances, $\mathrm{d} \sim 5$ to $25 \AA$.

Neither CDM nor DCDM can account for the major product ion charge states observed for streptavidin. Even with the use of infinitely late TS, the models underestimated the dominant charge state of the leaving subunit by one or two charges. It was proposed previously by Smith and coworkers the greater charge enrichment of the leaving subunit observed experimentally for the $\mathrm{S}_{4}^{n+}$ ions, compared to CDM, reflects unfolding of the subunit or possibly entropy effects [16].

Protein structure model (PSM). The lowest energy subunit charge state predicted by PSM at $\mathrm{d}=0$ and $\mathrm{d}=\infty$ for are listed in Table 2. It can be seen that PSM, both at early and late TS, yields charge states that are equivalent or lower than DCDM. The differences in PSM and DCDM results presumably reflect the differences in the spatial arrangement of the point charges. It is interesting to note that PSM predicts lower subunit charge states for Stx2 compared with Stx1. This result indicates that explicit consideration of the spatial arrangement of the (possible) charge sites leads to significant differences in the predicted lowest energy charge distribution. To account for the major subunit charge states observed for the $\mathrm{B}_{5}^{n \pm}$ ions of Stx1 and Stx2, PSM incorporating a late TS (i.e., $\mathrm{d} \sim 100 \AA$ for $\mathrm{Stx} 1$ and $\mathrm{d} \sim$ $50 \AA$ for Stx2) is required (data not shown). The use of a late TS for the electrostatic calculations and the spatial requirements for inter-subunit proton transfer can be reconciled by the fact that large displacement distances in the electrostatic calculations are, to a certain extent, equivalent to unfolding of the leaving subunit. To explore the possible effects of subunit unfolding on the product ion charge distribution, PSM was modified to consider cases where the leaving subunit is partially (PU-PSM) or fully unfolded (FU-PSM), Figure 1c and d. As expected, unfolding of the leaving subunit leads to an increase in predicted subunit charge state at a given $d$. At the same time, agreement between the experimental charge states and those predicted by PU-PSM is found at shorter TS distances compared to PSM. Agreement is found for the Stx $1 \mathrm{~B}_{5}^{n \pm}$ ions at $\mathrm{d} \leq 50 \AA$; much short distances are required for the Stx2 $\mathrm{B}_{5}^{n+}$ ions.

As mentioned above, the B subunits of Stx1 and Stx2 each contain a disulfide bond that prevents complete subunit unfolding. However, to gauge the effect of complete unfolding, the disulfide bond was omitted from the structures used for FU-PSM. According to the results in Table 2, FU-PSM overestimates the subunit charge state by two charges. Calculations were also carried out for Stx1 $\mathrm{B}_{5}^{+n}$ ions using a form of PSM in which all five of the B subunits were completely un- 

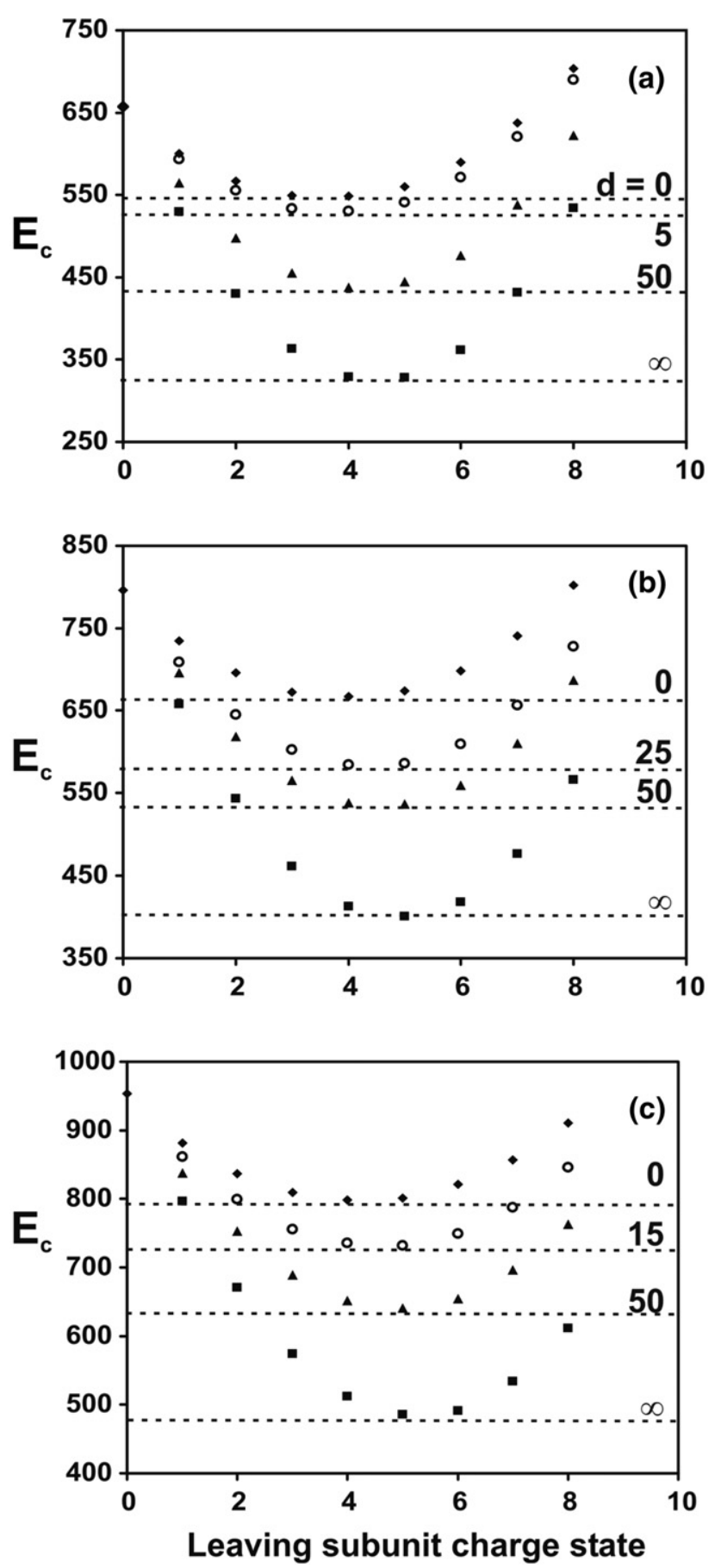

Figure 11. Coulombic energy profiles calculated using DCDM at the different TS distances, $d$ (in $\AA$ ), for the Stx $1 B_{5}^{n \pm}$ ions, where (a) $n=11$; (b) 12; and (c) 13. The TS distances considered are shown on the corresponding plots.

folded. In this case, the predicted charge distributions are identical to those obtained with PSM in which all subunits are in their native structure (data not shown). This result highlights the fact that equivalent unfolding of all of the subunits in multiprotein complex is not expected to influence the charge distribution in the product ions. However, equivalent unfolding may lead to differences in the $\Delta S^{\ddagger}$ values for the loss of subunit and may be at the origin of nonlinearity observed in some of the kinetic plots.

As with CDM/DCDM, PSM significantly underestimates the energetically preferred charge state for the $\mathrm{S}_{4}^{n+}$ ions. PU-PSM, as it was implemented in the present study, yields results that are closer to experiment, although there is still a slight underestimation of the degree of charge asymmetry. In PU-PSM, the partially unfolded subunit has a surface area of $\sim 11800 \AA^{2}$, compared with $\sim 7200 \AA^{2}$ for the native structure. In contrast, fully unfolding of the leaving subunit (FU-PSM), which results in a surface area of $\sim 15800 \AA^{2}$, leads consistently to an overestimation of the degree of charge asymmetry. These results suggest that the leaving subunit in the $\mathrm{S}_{4}^{n+}$ ions is significantly but not completely unfolded. It is notable that the higher order structure of the subunits of streptavidin is not constrained by a disulfide bond and the subunits can, in principle, undergo significant unfolding in the gas phase. Interestingly, it was recently shown by Robinson and coworkers that the partitioning of charge between the dissociation products observed for very large multiprotein complexes could be explained by the ratio of product ion surface areas, assuming that the leaving subunit is completely unfolded [41].

The above analysis indicates that relatively simple electrostatic models, such as DCDM or PSM, can account reasonably well for the degree of charge asymmetry observed experimentally for the dissociation of some multiprotein complexes in the gas phase. However, the results also suggest that the leaving subunit may unfold before dissociation and that the degree of unfolding is highly variable and dependent on the structure of the subunit/complex and can not be predicted a priori. In particular, disulfide bonds appear to significantly reduce the degree of unfolding of the subunits. This result is consistent with recent findings reported by Williams and coworkers [12, 13].

\section{Comparison of Experimental $E_{a}$ and Calculated $E_{c}$ Values for the $B_{5}^{\mathrm{n} \pm}$ and $S_{4}^{\mathrm{n}+}$ Ions}

Assuming that $\mathrm{E}_{\mathrm{a}, \mathrm{o}}$ is independent of charge state (i.e., the higher order structure of the subunits and complex is constant at all charge states), it follows from eq 9 that the difference in $\mathrm{E}_{\mathrm{a}}$ for a given complex at charge states $\mathrm{n}$ and $\mathrm{m}$ will be determined solely by the difference in the Coulombic repulsion term, $\Delta \mathrm{E}_{\mathrm{c}(\mathrm{n}, \mathrm{m})}$ :

$$
\begin{aligned}
\Delta \mathrm{E}_{\mathrm{a}(\mathrm{n}, \mathrm{m})} & =\mathrm{E}_{\mathrm{a}, \mathrm{n}}-\mathrm{E}_{\mathrm{a}, \mathrm{m}} \\
& =\left[\mathrm{E}_{\mathrm{a}, \mathrm{o}}+\left(\mathrm{E}_{\mathrm{c}, \mathrm{n}}^{\ddagger}-\mathrm{E}_{\mathrm{c}, \mathrm{n}}^{\mathrm{o}}\right)\right]-\left[\mathrm{E}_{\mathrm{a}, \mathrm{o}}+\left(\mathrm{E}_{\mathrm{c}, \mathrm{m}}^{\ddagger}-\mathrm{E}_{\mathrm{c}, \mathrm{m}}^{\mathrm{o}}\right)\right]
\end{aligned}
$$

$$
=\left(E_{c, n}^{\ddagger}-E_{c, n}^{o}\right)-\left(E_{c, m}^{\ddagger}-E_{c, m}^{o}\right)=\Delta E_{c(n, m)}
$$

The change in Coulombic repulsion energy with charge state can, therefore, be determined from the 
difference in the dissociation $\mathrm{E}_{\mathrm{a}}$ values $\left(\Delta \mathrm{E}_{\mathrm{a}}\right)$ determined experimentally over a range of charge states.

Shown in Figure 12a is a plot of the experimental $E_{a}$ values determined for the Stx $1 \mathrm{~B}_{5}^{n \pm}$ ions at $n=10$ to 14 versus the $-\left(E_{c}^{\ddagger}-E_{c}^{o}\right)$ terms calculated with DCDM.
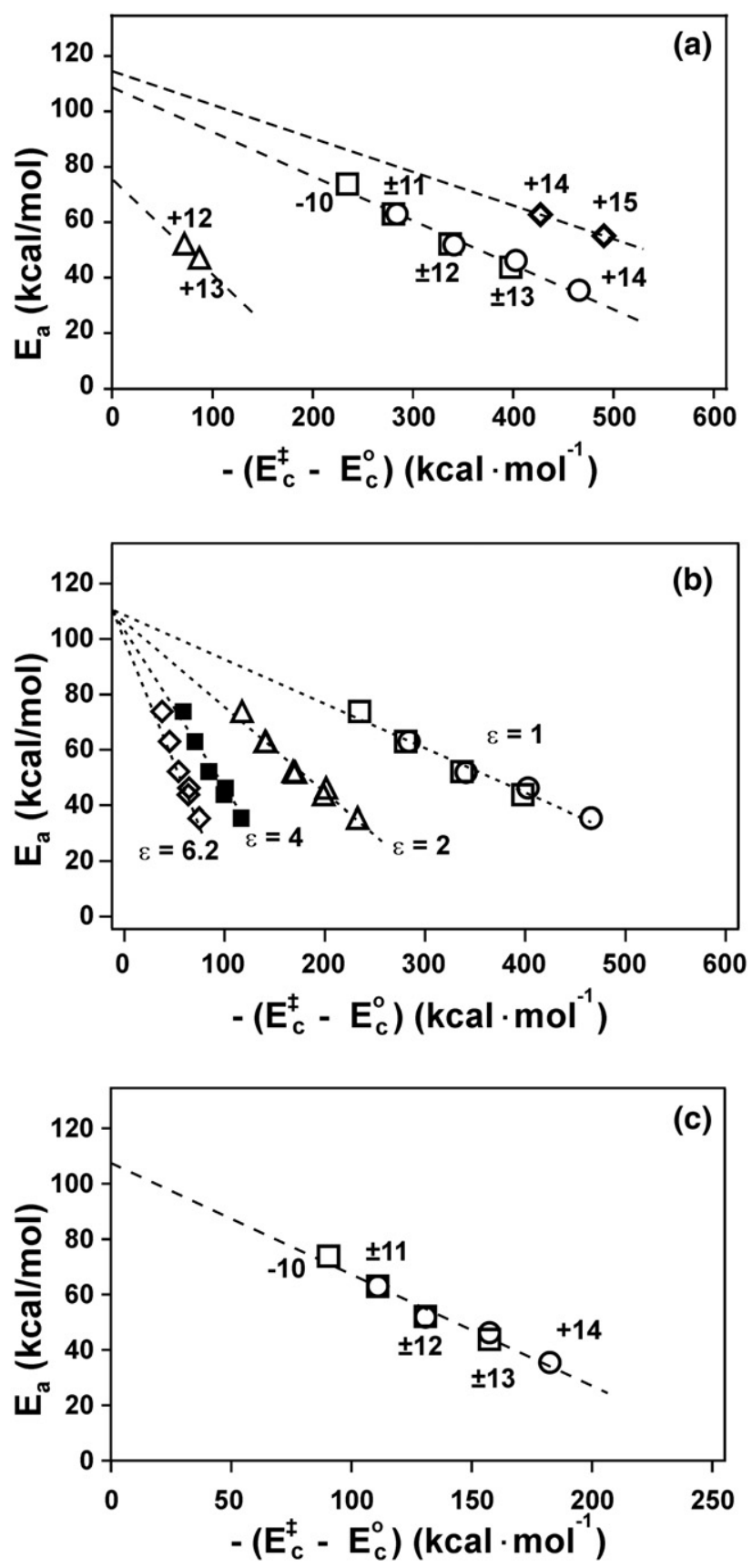

Figure 12. (a) Plot of the experimental $\mathrm{E}_{\mathrm{a}}$ values determined for the $\mathrm{B}_{5}^{n \pm}$ ions of $\mathrm{Stx} 1$ and $\mathrm{Stx} 2$ and $\mathrm{S}_{4}^{+n}$ ions versus $-\left(\mathrm{E}_{\mathrm{c}}^{\ddagger}-\mathrm{E}_{\mathrm{c}}^{\mathrm{o}}\right)$. The $-\left(\mathrm{E}_{\mathrm{c}}^{\ddagger}-\mathrm{E}_{\mathrm{c}}^{\mathrm{o}}\right)$ terms were calculated using DCDM at late TS $(\mathrm{d}=\infty)$ for (open circle) Stx1 $\mathrm{B}_{5}^{n+}$ and (open square) Stx1 $\mathrm{B}_{5}^{n-}$ ions; using DCDM and an early TS $(\mathrm{d}=0)$ for (open triangle) Stx2 $\mathrm{B}_{5}^{n+}$ ions and PU-PSM for (open diamond), $\mathrm{S}_{4}^{+n}$ ions. (b) Influence of $\varepsilon$ on the correlation plot between $E_{a}$ and the $-\left(E_{c}^{\ddagger}-E_{c}^{o}\right)$ term for Stx1 $\mathrm{B}_{5}^{n \pm}$ ions. (c) Plot of the experimental $\mathrm{E}_{\mathrm{a}}$ values determined for the Stx $1 B_{5}^{n \pm}$ ions versus $-\left(E_{c}^{\ddagger}-E_{c}^{o}\right)$, where the $-\left(E_{c}^{\ddagger}-E_{c}^{o}\right)$ terms were calculated using DCDM at a TS distance of $50 \AA$.
The $E_{c}^{o}$ and $E_{c}^{\ddagger}$ values correspond to the minimum energy charge distribution at $\mathrm{d}=0$ and $\infty$, respectively. It can be seen that there is a reasonably good linear relationship $\left(R^{2}=0.983\right)$ between the experimental and calculated values. A linear least-squares fit of the curve gives a slope of $0.16 \pm 0.01$ and $y$-intercept of $108.6 \pm$ $3.7 \mathrm{kcal} / \mathrm{mol}$. The fact that the slope is significantly smaller than 1.0 indicates that the calculated $-\left(\mathrm{E}_{\mathrm{c}}^{\ddagger}-\mathrm{E}_{\mathrm{c}}^{\mathrm{o}}\right)$ terms overestimate the actual contribution of Coulombic repulsion to the dissociation $\mathrm{E}_{\mathrm{a}}$. The overestimation of the electrostatic terms may be due to a number of factors, including the choice of $\varepsilon$ and the TS distance. Because some shielding of the charged groups by the protein subunits is likely, the use of a dielectric constant $>1.0$, which would result in a decrease in the magnitude of the $\left(\mathrm{E}_{\mathrm{c}}^{\ddagger}-\mathrm{E}_{\mathrm{c}}^{\mathrm{o}}\right)$ terms, is warranted. The effect of the $\varepsilon$ value is demonstrated in Figure 12b. Scaling down the $-\left(E_{c}^{\ddagger}-E_{c}^{o}\right)$ terms, by increasing the value of $\varepsilon$, raises the slope of the plot but does not change the y-intercept; an $\varepsilon$ value of 6.2 yields a plot with a slope of 1.0. Also, the use of an infinitely late TS $(\mathrm{d}=\infty)$ is expected to contribute significantly to an overestimation of the $-\left(E_{c}^{\ddagger}-E_{c}^{o}\right)$ values. Shown in Figure $12 c$ is a plot of $E_{a}$ versus $-\left(E_{c}^{\ddagger}-E_{c}^{o}\right)$ in which the $E_{c}^{\ddagger}$ values were calculated at $\mathrm{d}=50 \AA$. The slope of the plot is $0.40 \pm 0.03$, markedly larger than that obtained for $\mathrm{d}=\infty$, but the y-intercept (107.6 \pm 3.9$)$ is essentially unchanged.

A similar analysis was performed for the Stx2 $\mathrm{B}_{5}^{n+}$ $(D C D M, d=0)$ and $S_{4}^{n+}$ ions (PU-PSM, $d=\infty$ ). An $E_{a, o}$ value of $77 \mathrm{kcal} / \mathrm{mol}$ was determined for the Stx2 $\mathrm{B}_{5}^{n+}$ ions. This value is $\sim 30 \mathrm{kcal} / \mathrm{mol}$ smaller than that of Stx1 $B_{5}^{n \pm}$. Because $E_{a}$ values were available for only two charge states for the Stx $2 \mathrm{~B}_{5}^{n+}$ ions, the $\mathrm{E}_{\mathrm{a}, \mathrm{o}}$ value can only be considered a rough estimate. Nevertheless, this analysis suggests that the Stx2 $B_{5}$ is significantly less stable energetically than Stx $1 B_{5}$ in the gas phase. This is an interesting finding since it was recently shown that, in aqueous ammonium acetate solution, that Stx2 $B_{5}$ is also thermodynamically less stable than Stx1 $B_{5}$ [38]. In contrast, the Arrhenius parameters for the dissociation of the gaseous $\mathrm{B}_{5}^{n+}$ ions of Stx1 and Stx2, where $n=12$, 13 , are indistinguishable for the same charge state [38]. These findings highlight the importance of taking into account the contribution of Coulombic repulsion when comparing the relative stabilities of structurally distinct multiprotein complexes in the gas phase. For the $S_{4}^{n+}$ ions, an $\mathrm{E}_{\mathrm{a}, \mathrm{o}}$ value of $\sim 115 \mathrm{kcal} / \mathrm{mol}$, was obtained. The larger $E_{a, o}$ value for $S_{4}$, compared with those for the Stxs, is consistent with the greater thermal stability of $S_{4}$ in solution.

\section{$B / B_{4}$ versus $B_{2} / B_{3}$ dissociation pathways} for the $B_{5}^{\mathrm{n} \pm}$ ions

In the above analysis, it was shown that the partitioning of charge between the $\mathrm{B} / \mathrm{B}_{4}$ product ions produced by the dissociation of the $B_{5}^{n \pm}$ ions of Stx 1 and Stx 2 can be accounted for using simple electrostatic models. An 
interesting question to ask is whether these models can also provide explanation for the preferential dissociation of the $\mathrm{B}_{5}^{n+}$ ions via the $\mathrm{B} / \mathrm{B}_{4}$ pathway, instead of the $\mathrm{B}_{2} / \mathrm{B}_{3}$ pathway.

As was done for the $\mathrm{B} / \mathrm{B}_{4}$ pathway (eq 10), the dissociation $E_{a}$ for the $B_{2} / B_{3}$ pathway can be described as the sum of two terms, the intrinsic activation energy $\left(\mathrm{E}_{\mathrm{a}, \mathrm{o}}\right)_{(\mathrm{B} 2 /}$ B3) and an electrostatic term $\left(\mathrm{E}_{\mathrm{c}(\mathrm{B} 2 / \mathrm{B} 3)}^{\ddagger}-\mathrm{E}_{\mathrm{c}(\mathrm{B} 2 / \mathrm{B} 3)}^{\mathrm{o}}\right)$. It can be shown that the difference in the $E_{a}$ values between the $\mathrm{B} / \mathrm{B}_{4}$ and $\mathrm{B}_{2} / \mathrm{B}_{3}$ dissociation pathway is equivalent to the difference in intrinsic activation energy $\left(\mathrm{E}_{\mathrm{a}, \mathrm{o}}\right)$ and electrostatic term $\left(E_{c}^{\ddagger}-E_{c}^{o}\right)$ for the two pathways:

$$
\begin{aligned}
\mathrm{E}_{\mathrm{a}(\mathrm{B} / \mathrm{B} 4)}-\mathrm{E}_{\mathrm{a}(\mathrm{B} 2 / \mathrm{B} 3)}= & {\left[\mathrm{E}_{\mathrm{a}, \mathrm{o}(\mathrm{B} / \mathrm{B} 4)}+\left(\mathrm{E}_{\mathrm{c}(\mathrm{B} / \mathrm{B} 4)}^{\ddagger}-\mathrm{E}_{\mathrm{c}(\mathrm{B} / \mathrm{B} 4)}^{\mathrm{o}}\right)\right] } \\
& -\left[\mathrm{E}_{\mathrm{a}, \mathrm{O}(\mathrm{B} 2 / \mathrm{B} 3)}+\left(\mathrm{E}_{\mathrm{c}(\mathrm{B} 2 / \mathrm{B} 3)}^{\ddagger}-\mathrm{E}_{\mathrm{c}(\mathrm{B} 2 / \mathrm{B} 3)}^{\mathrm{o}}\right)\right]
\end{aligned}
$$

Because the dissociation reactions involve the same reactant ion (i.e., the reactions are parallel), the $\mathrm{E}_{\mathrm{c}(\mathrm{B} / \mathrm{B} 4)}^{\mathrm{d}}$ and $\mathrm{E}_{\mathrm{C}(\mathrm{B} 2 / \mathrm{B} 3)}^{\mathrm{o}}$ terms are equivalent and the expression can be further reduced:

$$
\begin{aligned}
\mathrm{E}_{\mathrm{a}(\mathrm{B} / \mathrm{B} 4)}-\mathrm{E}_{\mathrm{a}(\mathrm{B} 2 / \mathrm{B} 3)}= & {\left[\mathrm{E}_{\mathrm{a}, \mathrm{o}(\mathrm{B} / \mathrm{B} 4)}+\mathrm{E}_{\mathrm{c}(\mathrm{B} / \mathrm{B} 4)}^{\ddagger}\right] } \\
& -\left[\mathrm{E}_{\mathrm{a}, \mathrm{o}(\mathrm{B} 2 / \mathrm{B} 3)}+\mathrm{E}_{\mathrm{c}(\mathrm{B} 2 / \mathrm{B} 3)}^{\ddagger}\right]
\end{aligned}
$$

Assuming that the same number of intersubunit interactions must be broken to release a single subunit or a dimer and that no other structural changes accompany loss of the subunit, the $\mathrm{E}_{\mathrm{a}, \mathrm{o}}$ terms will also be equivalent and the energy difference for the two pathways will be determined solely by the difference in $\mathrm{E}_{\mathrm{c}}^{\ddagger}$ terms:

$$
\mathrm{E}_{\mathrm{a}(\mathrm{B} / \mathrm{B} 4)}-\mathrm{E}_{\mathrm{a}(\mathrm{B} 2 / \mathrm{B} 3)}=\mathrm{E}_{\mathrm{c}(\mathrm{B} / \mathrm{B} 4)}^{\ddagger}-\mathrm{E}_{\mathrm{c}(\mathrm{B} 2 / \mathrm{B} 3)}^{\ddagger}=\Delta \mathrm{E}_{\mathrm{c}}^{\ddagger}
$$

Using DCDM, the values of $\mathrm{E}_{\mathrm{c}}^{\ddagger}$ for the preferred product ion charge states for the two pathways at $\mathrm{d}=$ 0 and $\mathrm{d}=\infty$ were calculated for the Stx $1 \mathrm{~B}_{5}^{n \pm}$ ions. The difference in the $\mathrm{E}_{\mathrm{c}}^{\ddagger}$ values, i.e., $\Delta \mathrm{E}_{\mathrm{c}}^{\ddagger}$ for the two pathways, are listed in Table 3 . It can be seen that at all charge states, the $\Delta \mathrm{E}_{\mathrm{c}}^{\ddagger}$ values calculated using DCDM are positive, which implies that the Coulombic repulsion term is greater for the $B_{2} / B_{3}$ dissociation pathway. Consequently, the dissociation $E_{a}$ for the $B_{2} / B_{3}$ path-

Table 3. The difference in calculated electrostatic energies predicted by DCDM for the $\mathrm{B}_{2} / \mathrm{B}_{3}$ and $\mathrm{B} / \mathrm{B}_{4}$ dissociation pathways of multiply charged Stx $1 B_{5}{ }^{n \pm}$ ions $^{\text {a }}$

\begin{tabular}{lrr}
\hline & \multicolumn{2}{c}{$\mathrm{E}_{(\mathrm{B} / \mathrm{B} 4)}^{ \pm}-\mathrm{E}_{(\mathrm{B} 2 / \mathrm{B} 3)}^{ \pm}$} \\
\cline { 2 - 3 } $\mathrm{B}_{5}^{\mathrm{n} \pm}$ & $\mathrm{d}=0$ & $\mathrm{~d}=\infty$ \\
\hline \hline $\mathrm{n}=10$ & 9.6 & 8.5 \\
11 & 14.3 & 18.3 \\
12 & 15.1 & 19.4 \\
13 & 17.7 & 24.1 \\
14 & 20.6 & 23.1 \\
\hline
\end{tabular}

${ }^{\mathrm{a} E n e r g i e s}$ reported in units of $\mathrm{kcal} / \mathrm{mol}$. way should, based on the aforementioned assumptions, be smaller than the dissociation $\mathrm{E}_{\mathrm{a}}$ for the $\mathrm{B} / \mathrm{B}_{4}$ pathway. Therefore, by considering only electrostatic arguments and assuming similar $\mathrm{E}_{\mathrm{a}, \mathrm{o}}$ values for both pathways, the $B_{2} / B_{3}$ dissociation pathway would be expected to dominate, which does not agree with the experimental results. The lack of agreement between the theoretical and experimental results could be due to a number of reasons. First, given that the leaving subunit in the $\mathrm{B} / \mathrm{B}_{4}$ pathway is believed to undergo a certain degree of unfolding, the assumption that the $\mathrm{E}_{\mathrm{a}, \mathrm{o}}$ terms are equivalent for the two pathways is likely not valid. Secondly, the use of a single TS distance for the energy calculations for both pathways may not be appropriate, particularly if the degree of subunit unfolding for the two pathways is different.

\section{Conclusions}

In the present work, time-resolved thermal dissociation experiments were performed on the gaseous $B_{5}^{n \pm}$ ions of Stx 1 and Stx2 and the streptavidin $S_{4}^{n+}$ ions. Dissociation was found to proceed predominantly by the ejection of a single subunit, which retained between 34 to $50 \%$ of the total charge with the resulting multimer product ion being resistant to further dissociation. One of the most significant findings of the study is that the fractional (percent) charge transferred to the leaving subunit (for a given complex) is insensitive to the charge state of the complex, at least over the range of charge states investigated. This result suggests that the structures of the subunits within a given complex remain relatively constant at the different charge states. The Arrhenius activation parameters for the ejection of the subunit were found to be sensitive to the charge state of the complex; both $\mathrm{E}_{\mathrm{a}}$ and $\mathrm{A}$ decrease with increasing charge state. Interestingly, the parameters for the protonated and deprotonated Stx1 $\mathrm{B}_{5}^{n \pm}$ ions, with the same number of charges, are indistinguishable within experimental error. These results suggest long range Coulombic repulsion, as opposed to local charge solvation effects, governs the product ion charge distribution.

It was shown for the first time that simple electrostatic models, such as DCDM and PSM, can account for the influence of charge on the major dissociation pathways and the $E_{a}$ values for some multisubunit complexes. The major leaving subunit charge states observed for the Stx1 and Stx $2 \mathrm{~B}_{5}^{n \pm}$ ions correspond to the lowest energy charge distribution predicted by DCDM at a TS distance of between 5 and $25 \AA$. PSM, in which the subunits retain their native structure, predicts slightly less enrichment of charge for the leaving subunit compared to DCDM. However, by incorporating a certain degree of unfolding of the leaving subunit (PU-PSM), results similar to DCDM are obtained. Notably, different extents of subunit unfolding are needed to account for the major product ion charge states observed experimentally for the $B_{5}$ ions of Stx1 and Stx2. This result is intriguing, given the nearly identical higher order structure of the subunits predicted by X-ray 
analysis. The degree of charge asymmetry observed for the $\mathrm{S}_{4}^{n+}$ ions could not be accounted for with DCDM. Instead, PU-PSM incorporating significant unfolding of the leaving subunit was necessary to account for the degree of charge asymmetry. It is interesting to note that the higher order structure of the streptavidin subunits, in contrast to those of the Stxs, is not stabilized by disulfide bonds.

Taken together, these results suggest that the degree of unfolding of the leaving subunit can vary significantly between multiprotein complexes, even for structurally related complexes. In cases where the subunit is resistant to significant unfolding due to the presence of disulfide bonds, the degree of charge asymmetry observed in gas-phase dissociation experiments can be explained using DCDM. However, in cases where significant unfolding of the leaving subunit occurs, DCDM, as it was implemented in the present work, is inadequate. Instead, an electrostatic model that explicitly accounts for subunit unfolding is necessary. However, as revealed by the present study, the degree of subunit unfolding cannot be predicted a priori.

Using DCDM, the contributions of Coulombic repulsion to the dissociation $\mathrm{E}_{\mathrm{a}}$ for the Stx $\mathrm{B}_{5}^{n \pm}$ and $\mathrm{S}_{4}^{n+}$ ions were quantified, and the magnitude of the intrinsic dissociation energy, $\mathrm{E}_{\mathrm{a}, \mathrm{o}}$, was estimated for the first time. The $\mathrm{E}_{\mathrm{a}, \mathrm{o}}$ for the loss of a subunit from the Stx $1 \mathrm{~B}_{5}^{n \pm}$ ions was determined to be $\sim 108 \mathrm{kcal} / \mathrm{mol}$. A lower $\mathrm{E}_{\mathrm{a}, \mathrm{o}}$ value was determined for Stx $2 \mathrm{~B}_{5}^{n+}$ ions, $77 \mathrm{kcal} / \mathrm{mol}$, which is consistent with its lower thermodynamic stability of Stx2 $B_{5}$, relative to Stx $1 B_{5}$, in aqueous solution. The largest $E_{a, o}$ value, $115 \mathrm{kcal} / \mathrm{mol}$, was determined for the $S_{4}^{n+}$ ions. This finding is, qualitatively, consistent with greater stability of this homotetramer, relative to the Stx homopentamers, towards thermal-induced disassembly in solution.

\section{Acknowledgments}

The authors acknowledge the Natural Sciences and Engineering Research Council of Canada and the Alberta Ingenuity Center for Carbohydrate Science for generous funding. The authors also thank G. Armstrong for generously providing purified B subunit of Stx1 and Stx2 and P. Kebarle for helpful comments during the preparation of the manuscript.

\section{References}

1. Loo, J. A. Mass Spectrom. Rev. 1997, 16, 1-23.

2. Fandrich, M.; Tito, M. A.; Leroux, M. R.; Rostom, A. A.; Hartl, F. U.; Dobson, C. M.; Robinson, C. V. Proc. Natl. Acad. Sci. U.S.A. 2000, 97, 14151-14155.
3. Sobott, F.; Benesch, J. L. P.; Vierling, E.; Robinson, C. V. J. Biol. Chem. 2002, 277, 38921-38929;

4. Keetch, C. A.; Bromley, E. H. C.; McCammon, M. G.; Robinson, C. V. J. Biol. Chem. 2005, 280, 41667-41674.

5. Daniel, J. M.; Friess, S. D.; Rajagopalan, S.; Wendt, S.; Zenobi, R. Int. J. Mass Spectrom. 2002, 216, 1-27.

6. Winston, R. L.; Fitzgerald, M. C. Mass Spectrom. Rev. 1997, 16, 165-179.

7. Veenstra, T. D. Biochem. Biophys. Res. Commun. 1999, 257, 1-5.

8. Benesch, J. L. P.; Robinson, C. V. Curr. Opin. Struct. Biol. 2006, 16 245-251.

9. Heck, A. J. R.; van den Heuvel, R. H. H. Mass Spectrom. Rev. 2004, 23, 368-389.

10. Versluis, C.; Heck, A. J. R. Int. J. Mass Spectrom. 2001, 210, 637-649.

11. Felitsyn, N.; Kitova, E. N.; Klassen, J. S. J. Am. Soc. Mass Spectrom. 2002, 13, 1432-1442.

12. Jurchen, J. C.; Williams, E. R. J. Am. Chem. Soc. 2003, 125, 2817-2826.

13. Jurchen, J. C.; Garcia, D. E.; Williams, E. R. J. Am. Soc. Mass Spectrom. 2004, 15, 1408-1415.

14. Mauk, M. R.; Mauk, A. G.; Chen, Y. L.; Douglas, D. J. J. Am. Soc. Mass Spectrom. 2002, 13, 59-71.

15. Lightwahl, K. J.; Schwartz, B. L.; Smith, R. D. J. Am. Chem. Soc. 1994, 116 5271-5278.

16. Schwartz, B. L.; Bruce, J. E.; Anderson, G. A.; Hofstadler, S. A.; Rockwood, A. L.; Smith, R. D.; Chilkoti, A.; Stayton, P. S. J. Am. Soc. Mass Spectrom. 1995, 6, 459-465.

17. Sobott, F.; McCammon, M. G.; Robinson, C. V. Int. J. Mass Spectrom. 2003, 230, 193-200.

18. Felitsyn, N.; Kitova, E. N.; Klassen, J. S. Anal. Chem. 2001, 73, 4647-4661

19. van den Heuvel, R. H.; Heck, A. J. R. Curr. Opin. Chem. Biol. 2004, 8 $519-526$.

20. Pinkse, M. W.; Maier, C. S.; Kim, J. I.; Oh, B. H.; Heck, A. J. J. Mass Spectrom. 2003, 38, 315-320.

21. Rostom, A. A.; Fucini, P.; Benjamin, D. R.; Juenemann, R.; Nierhaus, K. H.; Hartl, F. U.; Dobson, C. M.; Robinson, C. V. Proc. Natl. Acad. Sci. U.S.A. 2000, 97, 5185-5190.

22. Loo, J. A.; Berhane, B.; Kaddis, C. S.; Wooding, K. M.; Xie, Y.; Kaufman, S. L.; Chernushevich, I. V. J. Am. Soc. Mass Spectrom. 2005, 16, 998-1008.

23. Benesch, J. L. P.; Sobott, F.; Robinson, C. V. Anal. Chem. 2003, 75, 2208-2214

24. Breuker, K.; McLafferty, F. W. Angew. Chem. Int. Ed. 2003, 42, 4900-4904.

25. Sobott, F.; Robinson, C. V. Int. J. Mass Spectrom. 2004, 236, 25-32.

26. Ryce, S. A.; Wyman, R. R. Can. J. Phys. 1970, 48, 2571-2576.

27. Csiszar, S.; Thachuk, M. Can. J. Chem. 2004, 82, 1736-1744.

28. Marcato, P.; Mulvey, G.; Read, R. J.; Vander Helm, K.; Nation, P. N.; Armstrong, G. D. J. Infect. Dis. 2001, 183, 435-443.

29. Mulvey, G.; Vanmaele, R.; Mrazek, M.; Cahill, M.; Armstrong, G. D. J. Microbiol. Methods 1998, 32, 247-252.

30. Hunter, E. P.; Lias, S. G. J. Phys. Chem. Ref. Data 1998, 27, 3, 413-656.

31. Taft, R. W.; Anvia, F.; Taagepera, M.; Catalan, J.; Elguero, J. J. Am. Chem. Soc. 1986, 108, 3237-3239.

32. Catalina, M. I.; van den Heuvel, R. H. H.; van Duijn, E.; Heck, A. J. R. Chem. Eur. J. 2005, 11, 960-968.

33. Fischer, H.; Polikarpov, I.; Craievich, A. F. Protein Sci. 2004, 13, 2825 2828.

34. Gas-Phase Ion Chemistry Vol. II; Bowers, M. T., Ed.; Academic Press: New York, 1979, Chap. XI.

35. Ling, H., Boodhoo, A., Hazes, B., Cummings, M. D., Armstrong, G. D., Brunton, J. L., Read, R. J. Biochemistry 1998, 37, 1777-1788. Atomic coordinates available at http:/ /www.rcsb.org/pdb (PDB ID 1BOS).

36. Fraser, M. E., Fujinaga, M., Cherney, M. M., Melton-Celsa, A. R., Twiddy, E. M., O’Brien, A. D., James, M. N. G. J. Biol. Chem. 2004, 279, 27511-27517. Atomic coordinates available at http://www.rcsb.org/ pdb (PDB ID 1R4P).

37. Freitag, S., Le Trong, I., Klumb, L., Stayton, P. S., Stenkamp, R. E. Protein Sci. 1997, 6, 1157-1166. Atomic coordinates available at http://www. rcsb.org/pdb (PDB ID 1SWB).

38. Kitova, E. N.; Daneshfar, R.; Marcato, P.; Mulvey, G. L.; Armstrong, G.; Klassen, J. S. J. Am. Soc. Mass Spectrom. 2005, 16, 1957-1968.

39. Wang, W. J.; Kitova, E. N.; Sun, J. X.; Klassen, J. S. J. Am. Soc. Mass Spectrom. 2005, 16, 1583-1594.

40. Peshke, M.; Blades, A.; Kebarle, P. J. Am. Chem. Soc. 2002, 124, 11519 11530.

41. Benesch, J. L. P.; Aquilina, J. A.; Ruotolo, B. T.; Sobott, F.; Robinson, C. V. Chem. Biol. 2006, 13, 597-605. 